\title{
ATUALIZAÇOES/CURRENT COMMENTS
}

\author{
EQUIPE LOCAL DE SAÚDE. SUGESTÕES PARA A ABRANGÊNCIA \\ DE SUA CARACTERIZAÇÃO
}

Evelin Naked de Castro Sá *

R..

SÁ, E. N. de C. - Equipe local de saúde. Sugestões para a abrangência de sua caracterização. Rev. Saúde públ., S. Paulo, 10:75-102, 1976.

RESUMo: Na definiçâo da força de trabalho representada pela equipe local de saúde é condicionante a situação sócio-econômico-sanitária da área onde deva atuar, o tipo e o programa da unidade sanitária, a existência de outras agências e seus respectivos programas, as condições materiais de instalação e $a$ distribuição espacial da rede. E analisado o modelo de dimensionamento de recursos humanos para a rede de unidades sanitárias da Secretaria de Estado da Saúde (São Paulo, Brasil). A implantação de um modelo vai evidenciar o grau de acerto com que foram previstas dificuldades e impedimentos externos, tais como a força de trabalho disponivel no mercado e as possibilidades institucionais de competir nesse mercado e de proceder a correção de situações encontradas.

Unitermos: Equipe local de saúde. Unidade sanitária local. Saúde pública.

\section{SIGNIFICADO E CONCEITO}

A eficiência de um serviço local de saúde depende, em grande parte, do pessoal responsável pela execução das atividades. Segundo Rodrigues "é no trabalho da unidade sanitária local que se cristalizam as diretrizes técnicas, se evidenciam, na prática, as teorias meditadas e concepções doutrinárias, transformadas em resultados concretos, bons ou maus, a positivarem a capacidade e a eficiência da máquina de saúde pública encarregada de proteger e restaurar a saúde ria população".

Equipe local de saúde significa, por outro lado, uma força de trabalho condicionada por dois tipos de determinantes: o que seja uma unidade sanitária local e os condicionantes no dimensionamento $\mathrm{da}$ equipe; originarão perguntas tais como: "que tipo e quantidade de recursos humanos?" "para fazer o que?" e "onde?".

\section{A UNIDADE SANITARIA LOCAL}

É variado o conjunto de tipos de unidades sanitárias locais. Para Rodrigues ${ }^{6}$ são modalidades de unidade sanitária local o hospital, o centro e posto de saúde,

* Da Secretaria de Estado da Saúde. Av. São Luiz, 99 - São Paulo, SP - Brasil.

Do Departamento de Prática de Saúde Pública da Faculdade de Saúde Pública da USP. Av. Dr. Arnaldo, 715 - São Paulo, SP - Brasil. 
SA, E. N. de C. - Equipe local de saúde. Sugestões para a abrangência de sua caracterização. Rev. Saúde públ., S. Paulo, 10:75-102, 1976.

o dispensário, a clínica e posto volante, "onde atende diretamente o público, assistindo e orientando os indivíduos nos próprios domicílios, nos locais de trabalho e nas escolas, por intermédio de auxiliares qualificados".

Já para Mascarenhas ${ }^{5}$ a diferenciação se estabelece mais no sentido da especialidade ou polivalência do serviço de saúde oferecido e no caráter estático ou dinâmico da unidade, do que propriamente na denominação. As denominaçōes encontradas nos vários países não encontram um denominador comum ordenado: centro de saúde, posto de higiene, dispensário de tuberculose, de lepra, de malária, de puericultura, policlínica, etc., mas podem, porém, serem classificadas com relativamente pequeno afastamento, sob rótulos mais abrangentes. Três tipos básicos podem ser considerados: a) o ambulatório, criado para atender a determinada doença ou grupo de doenças ou a determinado grupo etário especializado, recebendo apenas os que procuram a unidade, seja por se sentirem doentes ou suspeitos de doença, seja para receberem outro tipo de atenção ou benefício (estático). Neste tipo são considerados os postos de puericultura que atendem gestantes e crianças até determinada idade de certas zonas, os dispensários de lepra cuja clientela é formada pelos doentes suspeitos e comunicantes da Hanseníase; também as unidades que têm uma polivalência relativa mas não possuem nenhuma ação extra-unidade podem ser classificadas como uma reunião de ambulatórios, assim como os ambulatórios de hospitais gerais ou especializados; b) dispensário, considerado especializado e dinâmico e atendendo não só os doentes suspeitos e comunicantes, mas também alcançando a população supostamente sadia através de medidas preventivas; c) centro de saúde, considerado polivalente na medida em que executa várias atividades de saúde pública e dinâmico porque necessariamente pressupöe visitação sanitária, esta também polivalente, e atuando sob chefia única. As vá- rias denominações encontradas: posto de saúde, posto de higiene, policlínica de saúde, etc., podem ser consideradas sinônimos se essas unidades tiverem as características de polivalência, dinamismo e comando único.

A polivalência refletirá a necessidade de atender as condiçôes médico-sanitárias e sócio-econômicas da área a que deve servir e. assim, nem mesmo a freqüência com que se usam denominações iguais e se dão estruturas iguais, tirará o caráter próprio de cada centro de saúde, sesundo Paula Souza. citado por Mascarenhas ${ }^{5}$ (a figura 1 ilustra as diferenças entre os três tipos de unidades). Somando-se àquela diferenciação a diversidade de evolução dos serviços de saúde pública em cada país ou região. temos, como conseqüencia, também, diferentes conceitos de centro de saúde. Mascarenhas ${ }^{5}$ enumera definições de Willinsky, da Conferência Européia de Higiene Rural. Carreño, Barros Barreto e da Organização Mundial de Saúde que incluem, entre outras características, a localização ou não em um mesmo edifício, a promoção da saúde junto com o bem estar do povo realizadas por órgãos governamentais e particulares, centralizadamente ou não. A chefia única é citada em praticamente todos os r'asos e é freqüente a citação da assistência púbìca ou assistência social como parte irtegrante das atividades e também a incorporação das atividades de medicina curativa entre as preventivas e as assistenciais.

A definição da Organização Mundial de Saúde citada por Rodrigues ${ }^{6}$ "unidade que assegura as funções essenciais da medicina curativa, preventiva e de higiene, que são necessárias para a maioria da população local, seja diretamente ou em coordenação com outros serviços" está complementada pela tentativa dos peritos em identificar os tipos de Centros de Saúde: "em que este seria parte de uma unidade sanitária local com âmbito de atividades muito maior, o centro constituindo a própria unidade e o centro como centro de diagnóstico servindo a várias outras 
SA, E. N. de C. - Equipe local de saúde. Sugestões para a abrangência de sua caracterização. Rev. Saúde puibl., S. Paulo, 10:75-102, 1976.

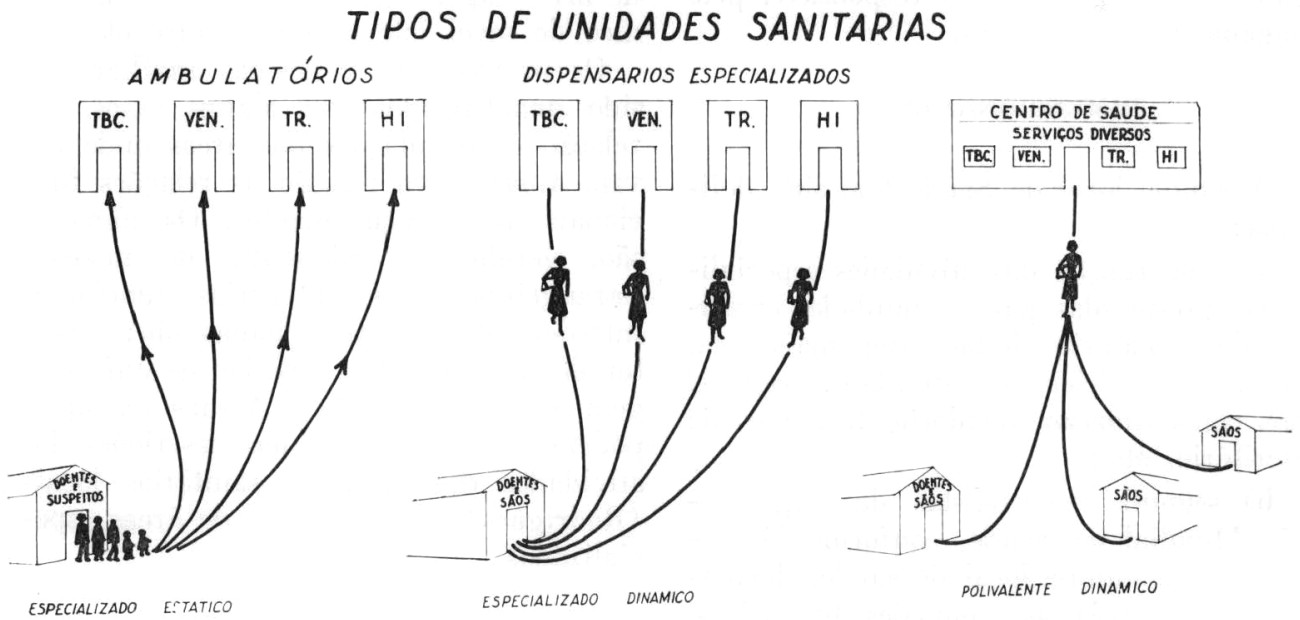

Fig. 1 - Tipos de unidades sanitárias. (Extraída de Mascarenhas 5, 1972).

unidades", sendo acentuado que "um centro de saúde é mais uma unidade funcional que uma entidade orgânica e sua estrutura deve adaptar-se às condiçôes e às exigências locais" ".

$\mathrm{Na}$ definição de Mascarenhas ${ }^{5}$ "Centro de Saúde é uma unidade dinâmica, responsável, sob uma chefia, pela execução de todas as atividades de saúde pública que possam ser descentralizadas em órgão local, em uma determinada área, que pode ser formada pela reunião de municípios, por um só município ou parte deste, neste caso, Distrito de $\mathrm{Paz}$ ou reunião destes em uma Capital".

Decorrentes dessa definição, temos os seguintes tipos:

a) sub-centro ou unidades-satélites ou com outra denominação, que executam atividades gerais, com uma retaguarda especializada localizada no Centro de Saúde mais próximo ou por especialistas no próprio subcentro;

b) unidade-sanitária-hospital, quando condiçôes locais ou regionais indicam a necessidade de prestação conjunta de serviços assistenciais e de medicina preventiva. Destacam-se, como exemplos:
- os casos em que o Estado necessita criar leitos hospitalares para atender à população; os dois órgãos são distintos um do outro, com atividades coordenadas num todo harmônico. Possuem, geralmente, uma chefia única, quase sempre de Sanitaristas;

- nas pequenas comunidades, onde não existe nenhuma assistência médicohospitalar e dificuldades de comunicar com centros maiores. As atendentes curativas são as que têm maior ênfase. É o médico clínico que executa, orientado pelo pessoal do Centro de Saúde, as atividades preventivas de maior importância local;

- em algumas regiōes da América Latina, casos de centros de saúde com alguns leitos para partos, desidratação etc. e que podem, em situaçōes de emergência, serem usados para doenças transmissiveis;

- centros de saúde onde se congregam atividades de medicina preventiva e de assistência médica também para grupos de pessoas com previdência social a cargo de outras fontes financiadoras. Nesse caso, as instalações do Centro de Saúde são utilizadas para atender a todas as atividades médicas, sem diferenciação do ór- 
SA, E. N. de C. - Equipe local de saúde. Sugestőes para a abrangência de sua caracterização. Rev. Saúde públ., S. Paulo, 10:75-102, 1976.

gão ou nível de governo responsável pelo pagamento dos serviços.

\section{DIMENSIONAMENTO}

A equipe local de Saúde tem sido definida:

a) em função das atividades especializadas presumidas para a unidade, constituindo somatório destas com mais ura previsão, empírica, das atividades comuns, tais como limpeza, zeladoria, trabalhos de escritório, etc.;

b) segundo especialistas da Organização Mundial de Saúde, conforme Mascarenhas ${ }^{B}$, a equipe local de saúde, devidamente adaptada às condições brasileiras, seria:

- mínima, constituída de médico, atendente, visitadora sanitária e fiscal ou auxiliar de saneamento, a existência da equjpe mínima, com 4 categorias, seria condição indispensável ao funcionamento da unidade;

- ideal, entre 15 e 20 categorias profissionais: médico-sanitarista, médicos clínicos para assistência sanitária (pediatra, nutricionista, enfermeiras, enfermeiras sanitárias, auxiliares de enfermagem, visitadoras, inspetores de saúde, fiscal sanitário, técnicos (laboratórios, raios $\mathrm{X}$, etc. e pessoal de escritório e de limpeza);

- possível, recrutável em curto espaço de tempo, em nível local, para sanar as faltas de pessoal especializado em saúde pública. O pessoal auxiliar seria treinado em cursos rápidos para visitadora sanitária, auxiliar de enfermagem ou atendente, auxiliar de saneamento, atendente dentário, etc. A enfermeira e o médico sanitarista seriam reservados para unidades médias e grandes. Como características do pessoal dos serviços de saúde dos países em desenvolvimento, são citadas (Rodrigues $^{6}$ ) : a utilização de pessoal de nível universitário sem o necessário preparo e de pessoal auxiliar indicado politicamente sem instrução geral ou de serviço; e as dificuldades de relacionamento entre pessoal de nível auxiliar e de profissionais de nível superior por falta de pessoal técnico de nível intermediário entre eles.

Os profissionais e pessoal auxiliar têm sido quantificados, em alguns casos, em relação às populações das áreas onde devam atuar e em relação às relações funcionais que devam manter. Os números são, geralmente, adaptados de modelos estrangeiros $e$ as categorias funcionais interdependentes mais citadas são: inspetor de saneamento $x$ auxiliar de enfermagem $x$ visitadora, etc. Alguns exemplos podem ser encontrados nas descrições das atividades das unidades sanitárias locais (Rodrigues ${ }^{6}$ ) e em planos de áreas especializadas.

\section{CONDICIONANTES}

A - Sócio-econômico. Os aspectos sócio-econômico sanitários são condicionantes do dimensionamento da equipe local de saúde, na medida em que representam em que grau a força de trabalho, que vai produzir ações de saúde, está adequada à realidade onde deva atuar. O nível de saúde de uma população e estágio de desenvolvimento da saúde pública em que se encontra a área são pontos a serem pesados no dimensionamento do pessoal, e a consulta a esses dados permite um melhor dimensionamento. $\mathbf{f}$. condicionante, por exemplo, a situação sanitária refletida nas curvas de mortalidade proporcional no município de São Paulo, calculadas a cada 5 anos (exceto 1904 a 1909) de 1894 a 1959, e para as regiōes administrativas do Estado de Sãc Paulo, nos períodos de 1950 a 1960 e 1967, conforme apresentadas por Guedes ${ }^{2}$ (Figs. 2, 3, 4 e 5). Ou, ainda, o coeficiente de mortalidade infantil, por área geográfica, no município de São Paulo, em 1971, relacionado por Yunes*, na Tabela 1. Também são exemplos de condicionantes os dados da "Investigação Intera-

* YUNES, J. et al. - Plano estadual de assistência integral à gestante, nutriz e crianca de 0 a 6 anos. S. Paulo, Secretaria do Planejamento, 1975. (inédito) 
1894

1899

1909

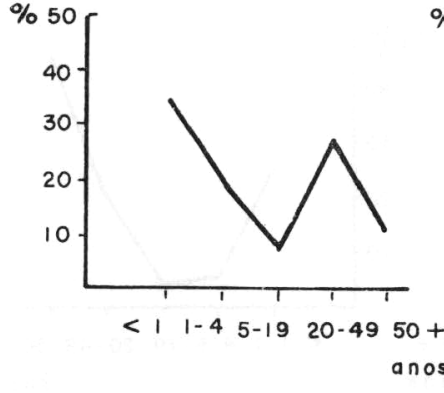

1914

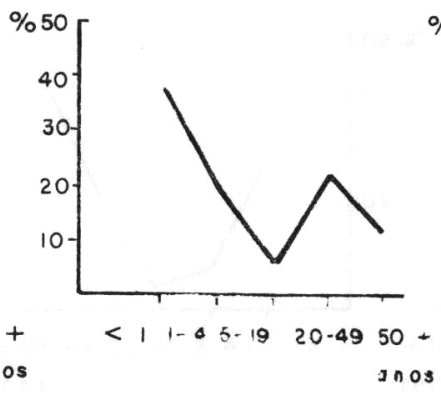

1924

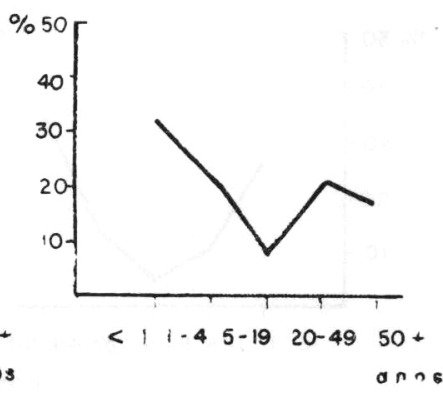

1929
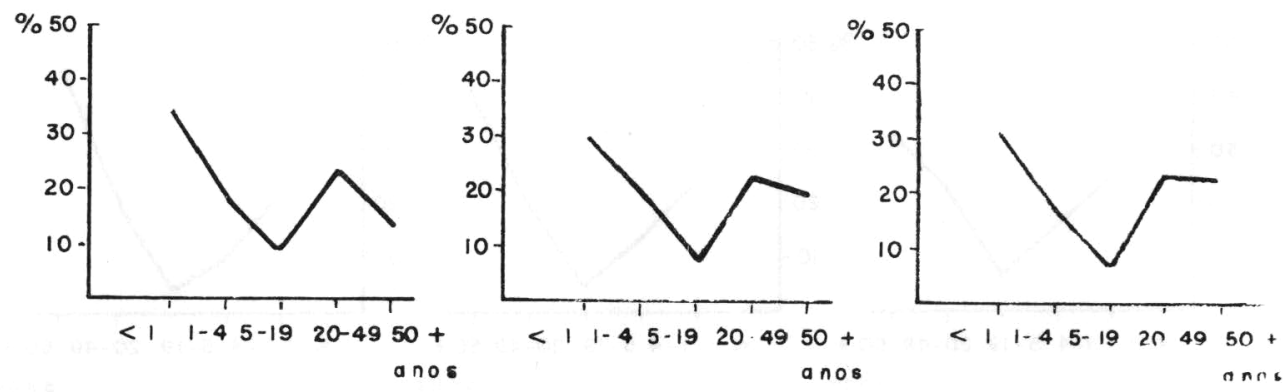

1934

1939

1944
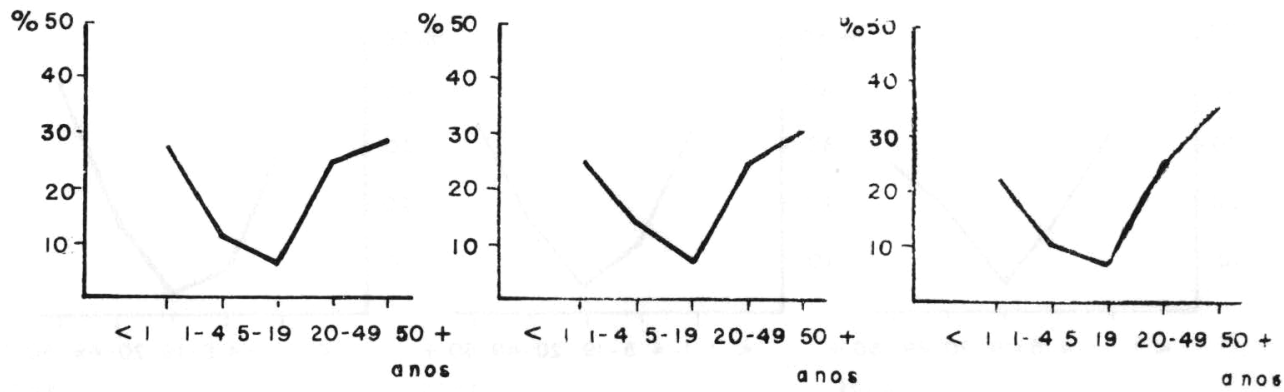

1949

1954

1959

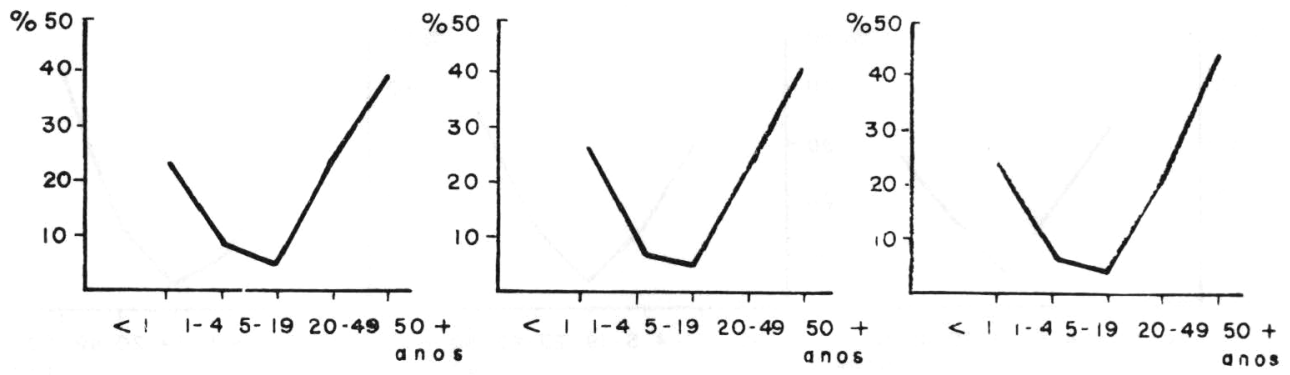

Fig. 2 - Curvas de mortalidade proporcional no município de São Paulo, a cada 5 anos (exceto 1904 a 1909) no periodo de 1894 a 1959. (Extraída de Guedes e Guedes 2, 1973). 
GRANDE SÃO PAULO
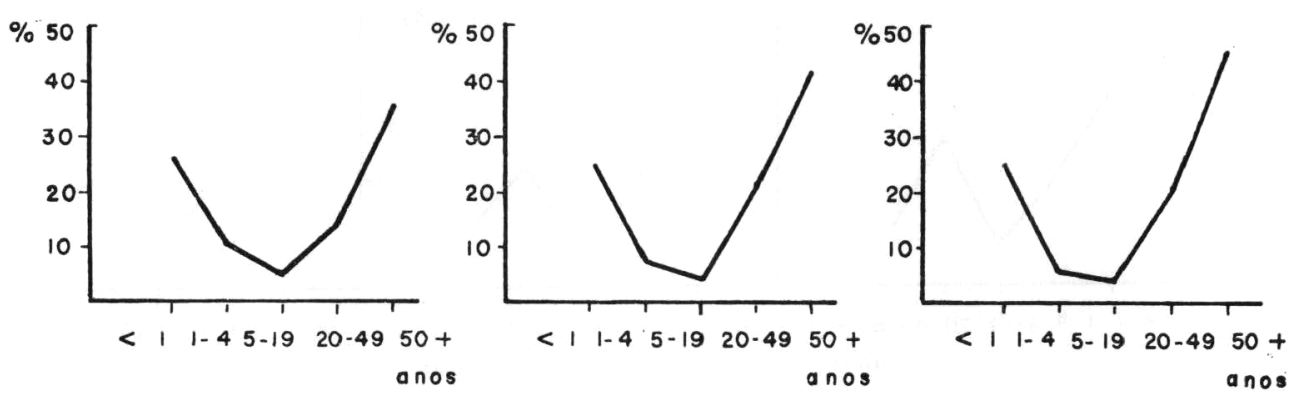

LI TORAL
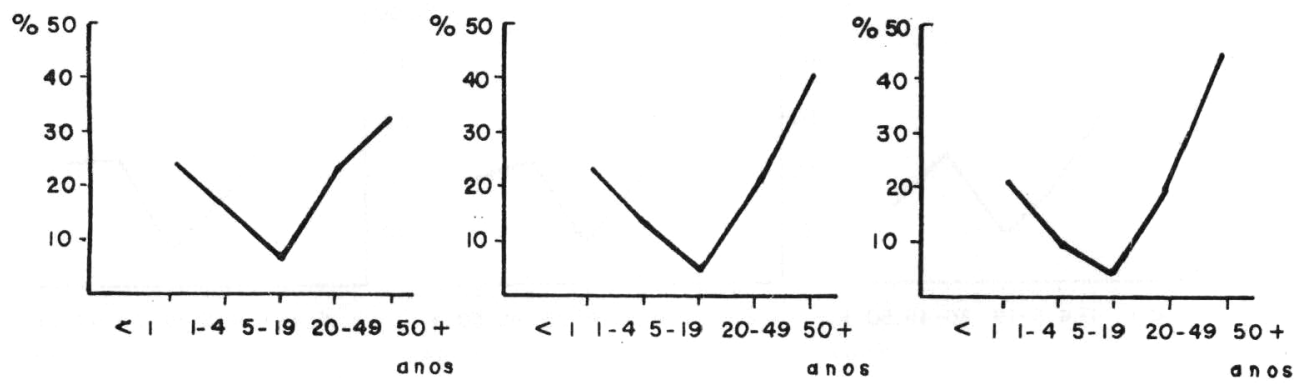

VALE DO PARAIBA
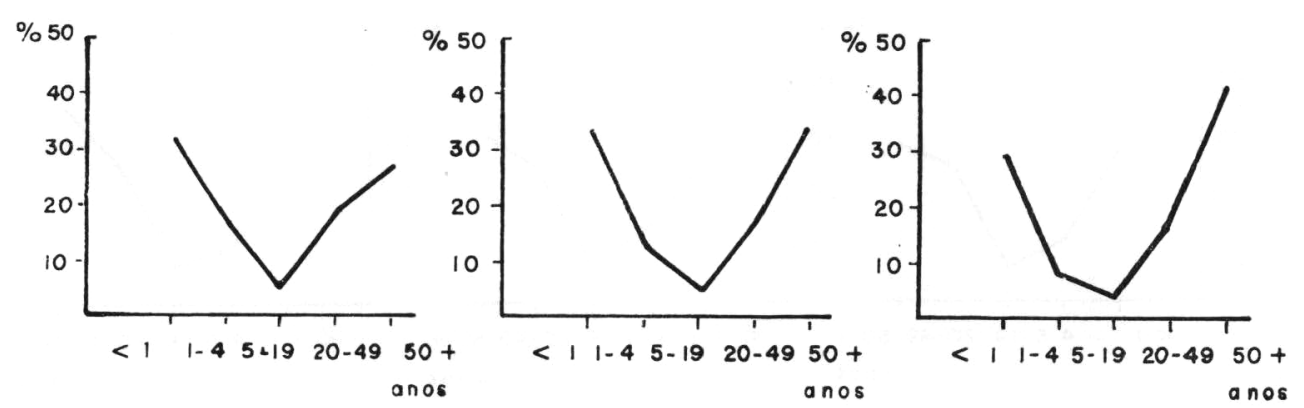

SOROCABA
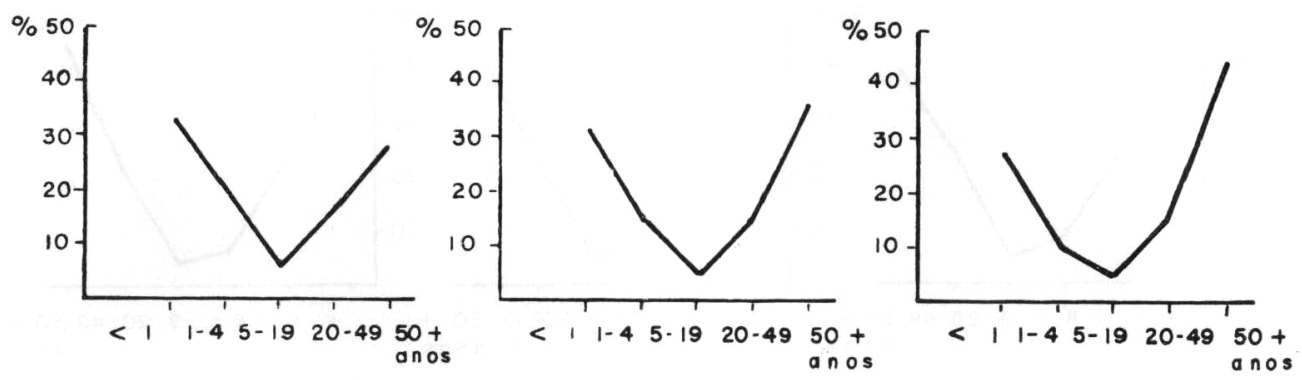

Fig. 3 - Curvas de mortalidade proporcional para as regiões administrativas do Estado de São Paulo. Dados médios para os períodos de 1950, 1960 e 1967. (Extraida de Guedes e Guedes 2, 1973). 
1950

1960

1967

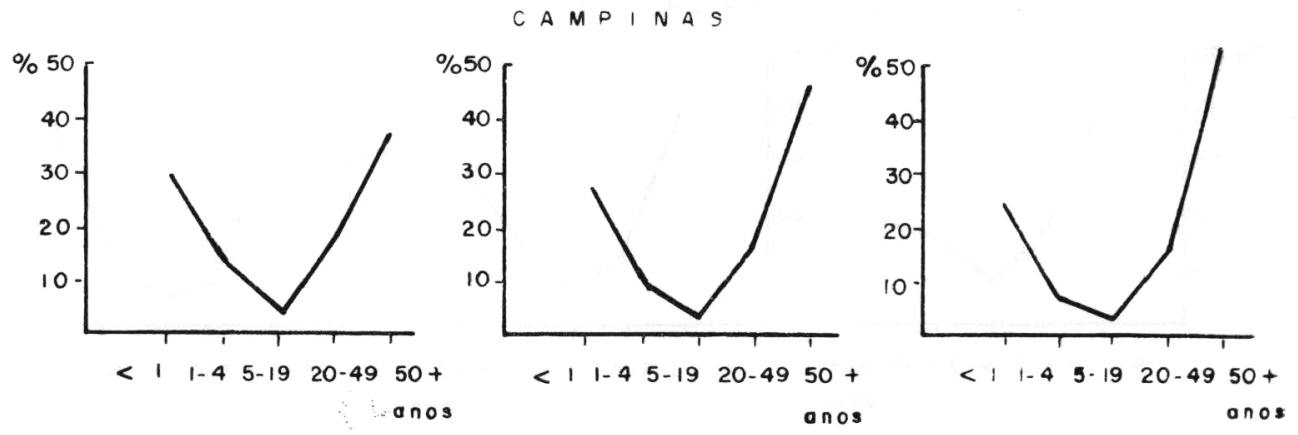

RIBEIRÃO PRETO
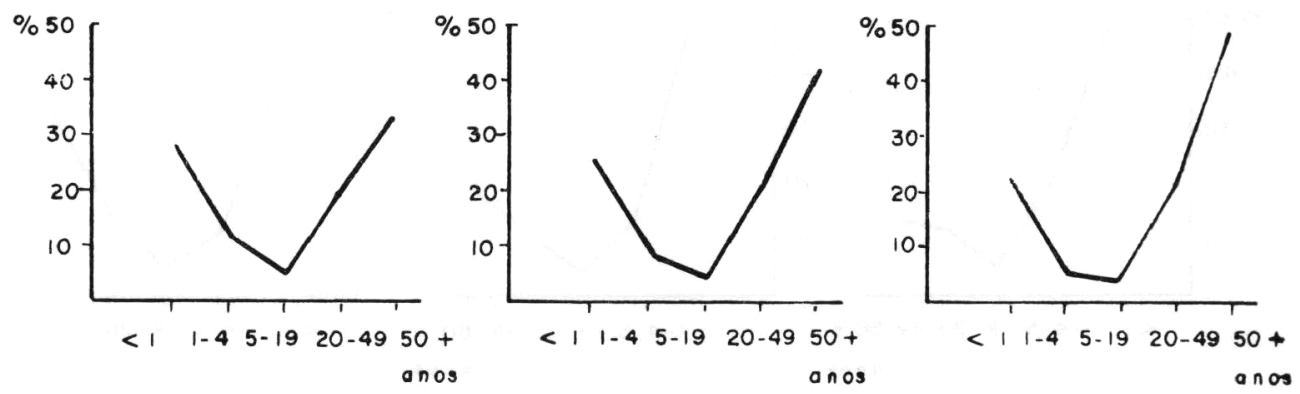

B A U R U
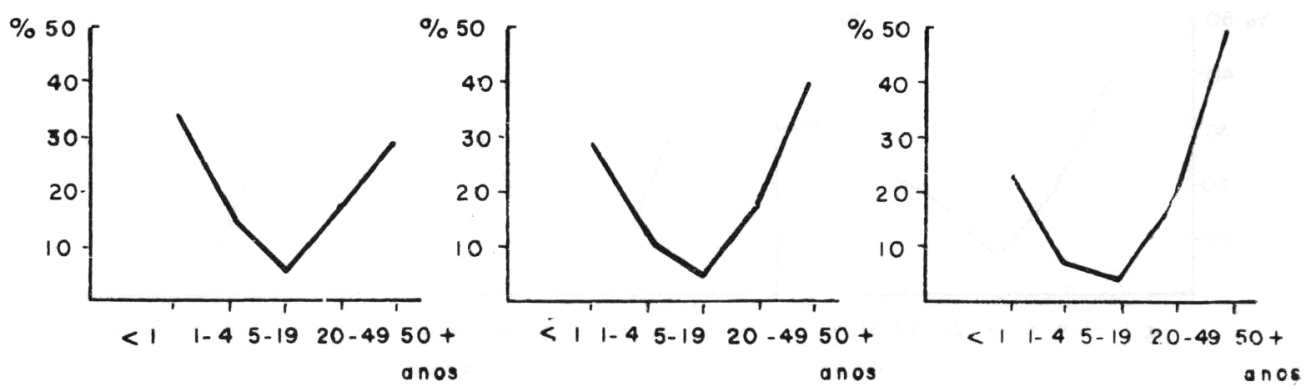

SÃO JOSÉ DO RIO PRETO
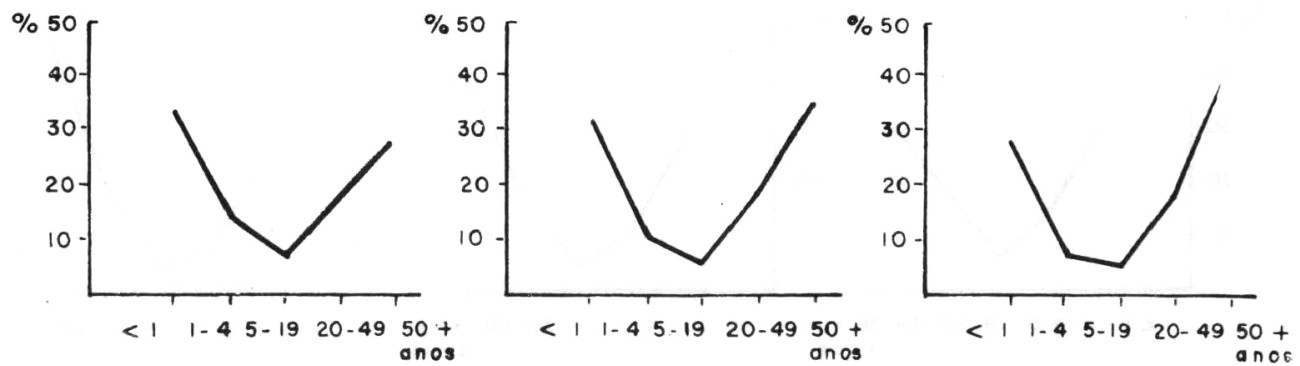

Fig. 4 - Curvas de mortalidade proporcional para as regioes administrativas do Estado de São Paulo. Dados médios para os periodos de 1950, 1960 e 1967. (Extraida de Guedes e Guedes 2, 1973). 
1950

1960

1967

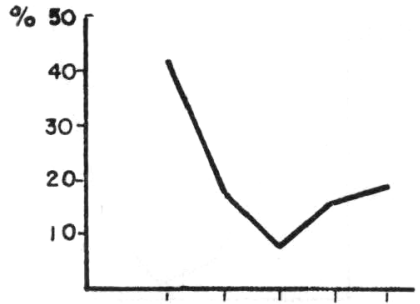

$<11-45-1920-4950+$

anos $\triangle R A C A T U B A$

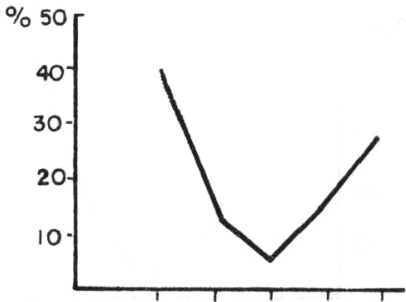

$<1-1-4$ 5-19 20-4950+

anos

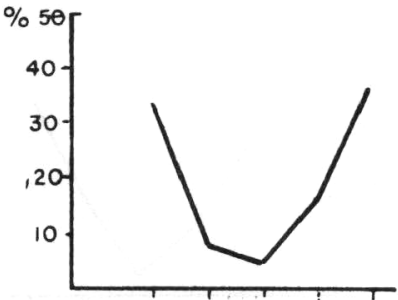

$<1 \quad 1-45-1920-4950+$

0 nos

PRESIDENTE PRUDENTE
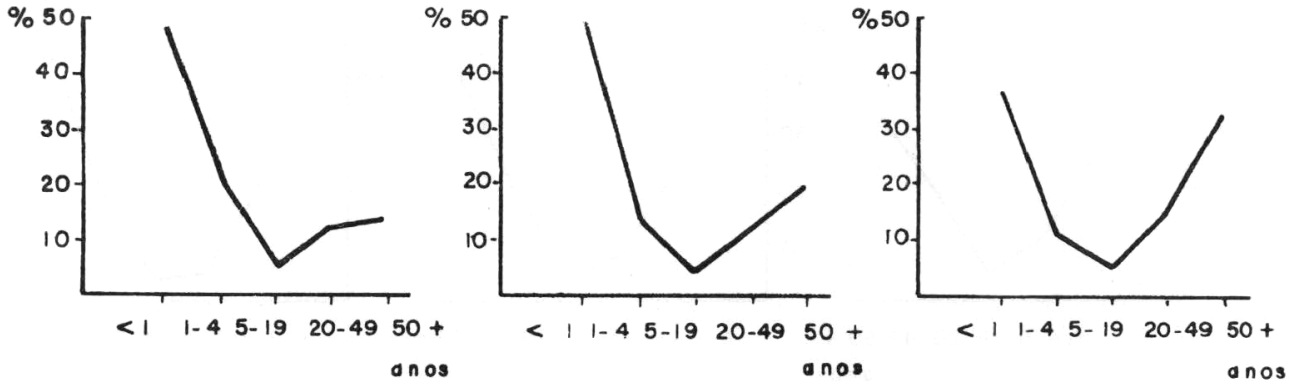

M $A R|L| A$

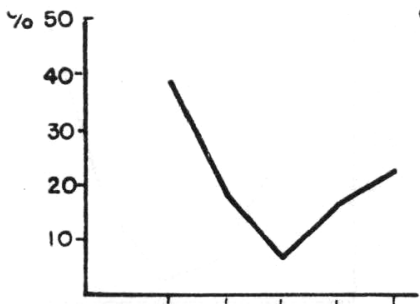

$<1 \quad 1-4 \quad 5-19 \quad 20-4950+$

anos

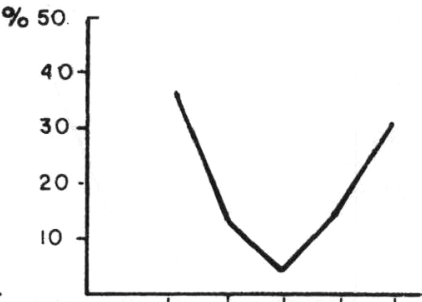

$<11-45-1920-4950+$

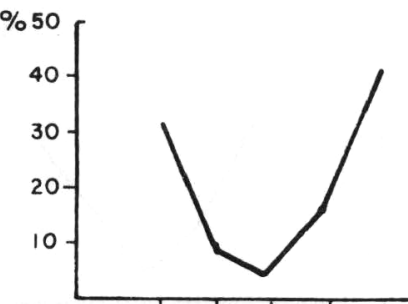

$<11-45-1920-4950+$

anos

Estado dE são paulo

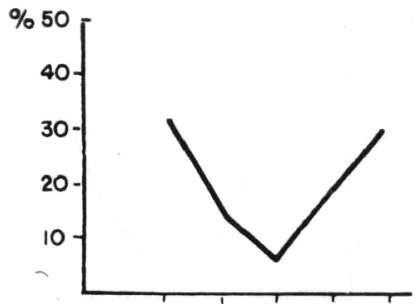

$\begin{array}{llll}<1 & 1-45-1920-49 & 50+ \\ 0 & \text { nos }\end{array}$
$\% 50$

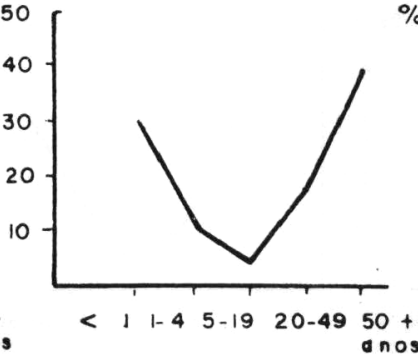

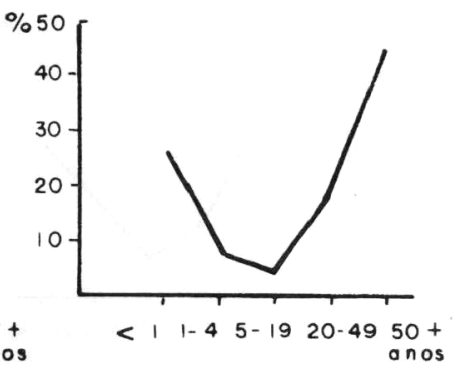

Fig. 5 - Curvas de mortalidade proporcional para as regiones administrativas do Estado de São Paulo. Dados médios para os periodos de 1950, 1960 e 1967. (Extraída de Guedes e Guedes ${ }^{2}$, 1973). 
SA, E. N. de C. - Equipe local de saúde. Sugestóes para a abrangência de sua caracterlzação. Rev. Saúde públ., S. Paulo, 10:75-102, 1976.

TABELA 1

Coeficiente de mortalidade infantil por área geográfica, no munlcíplo de săo Paulo, em 1971

\begin{tabular}{l|c|cc}
\hline Localidade & $\begin{array}{c}\text { Mortalidade } \\
\text { Infantil }\end{array}$ & $\begin{array}{c}\text { Mortalidade } \\
\text { neonatal }\end{array}$ & $\begin{array}{c}\text { Mortalidade } \\
\text { infantil tardia }\end{array}$ \\
\hline Municipio de săo Paulo & 85,38 & 40,02 & 45,37 \\
\hline Zona central & 64,71 & 35,29 & 29,92 \\
\hline Zona intermediária & 82,00 & $\mathbf{3 8 , 8 5}$ & 43,15 \\
\hline Zona periférica & 106,81 & 45,74 & 61,07 \\
\hline
\end{tabular}

Fonte: Yunes - op. cit.

T A B EL A 2

Proporção de óbitos de crianças menores de 1 ano e de 1 a 4 anos que apresentaram desnutrição como causa básica ou associada, em São Paulo e em outras áreas que participaram da "Investigação Interamericana de Mortalidade na Infâncla".

\begin{tabular}{|c|c|c|}
\hline Areas: & $\begin{array}{c}\text { Menores de } 1 \text { ano } \\
\%\end{array}$ & $\begin{array}{c}1 \text { a } 4 \text { anos } \\
\%\end{array}$ \\
\hline Recife & 38,9 & 70,0 \\
\hline $\begin{array}{l}\text { Ribeirāo Preto (área) } \\
\text { Cidade } \\
\text { Franca } \\
\text { Comunidades }\end{array}$ & $\begin{array}{l}28,8 \\
32,7 \\
32,9\end{array}$ & $\begin{array}{l}68,0 \\
55,0 \\
70,0\end{array}$ \\
\hline são Paulo & 28,0 & 46,0 \\
\hline La Paz & 27,0 & 51,5 \\
\hline $\begin{array}{c}\text { San Salvador (área) } \\
\text { Cidade } \\
\text { Area rural }\end{array}$ & $\begin{array}{l}28,5 \\
66,6\end{array}$ & $\begin{array}{l}65,3 \\
57,9\end{array}$ \\
\hline Sherbrooke & 1,9 & 9,0 \\
\hline S. Francisco & 4,7 & 12,0 \\
\hline
\end{tabular}

- Batatais, Brodosqui, Cravinhos, Jardinópolis e Sertãozinho.

Fonte: Leser (1974) 
SÁ, E. N. de C. - Equipe local de saúde. Sugestōes para a abrangência de sua caracterização. Rev. Saúde públ., S. Paulo, 10:75-102, 1976.

mericana de Mortalidade na Infância" (conforme Leser ${ }^{3}$ ) que permitiram caracterizar os aspectos ligados à mortalidade infantil e à de crianças de um a 4 anos, num período de 2 anos e que possibilitam comparar o $1 .^{\circ}$ Distrito do município de São Paulo com outras áreas brasileiras, latino-americanas e norteamericanas.

Lsando um indicador global, il surva de mortalidade proporcional, propostc por Nelson de Moraes, que inclui a razão de mortalidade proporcional de Swaroop e Uemura (óbitos de pessoas com 50 ou mais anos), Leser ${ }^{3}$ mostra que os dados do município de São Paulo referentes aos triênios 1949-1951, 1959-1961 e 1971, evidenciam estarmos ainda muito longe da curva em J, característica das regióes com

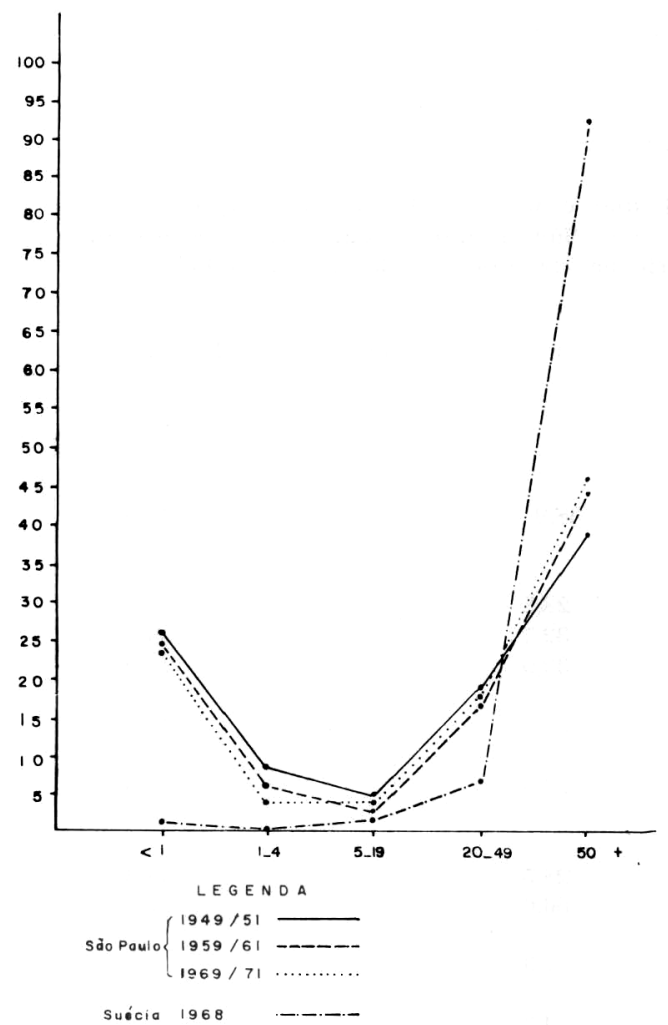

Fig. 6 - Curvas de mortalidade - Municipio de São Paulo (triênios 1949/51, 1959/61, 1969/71) e Suécia 1968. (Extraida de Leser ${ }^{3}$ 1975). nível de saúde elevado, em confronto com os dados referentes à Suécia em 1968, que estão refletidos em um J nítido (Fig. 6).

Reforçando o exemplo citado por Yunes", do indicador específico "coeficiente de mortalidade infantil" - um é dos mais expressivos indicadores de saúde de toda a população, já que é o mais sensível e reflete as condiçôes sociais e a eficiência dos serviços oferecidos à população -, Leser $^{4}$ a ele acrescenta, como reforço, a variação do poder aquisitivo representado pelo salário-mínimo real e pela percentagem da população que dispõe de água encanada. Temos, assim, na primeira curva o reflexo das 2 outras (Fig. 7). E, a deficiência nutricional (função do salário

* Dados inéditos.

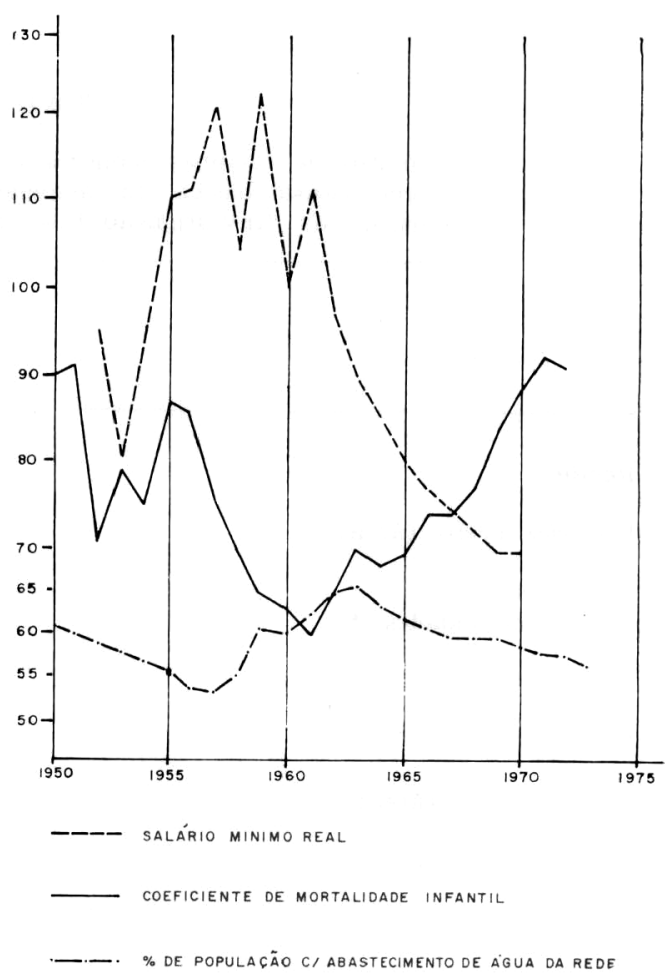

Fig. 7 - Coeficiente de mortalidade infantil, salário minimo real e, percentagem da população com abastecimento de água da rede. (Extraida de Leser ${ }^{4}$, 1975). 
SA, E. N. de C. - Equipe local de saúde. Sugestōes para a abrangêncla de sua caracterização. Rev. Saúde públ., S. Paulo, 10:75-102, 1976.

mínimo) e a diarréia (ausência de saneamento básico), entram em considerável percentagem como causa básica ou associada na mortalidade infantil, na mortalidade neonatal e na mortalidade pósneonatal (Tabela 3).
O grau de atraso das nossas condições de saúde é medido de forma negativa em 10 anos, segundo Leser ${ }^{3}$, que comparou a evolução dos valores da esperança de vida desde a década dos cinqüenta em que passou-se dos estágio II para o III, quase

T A B E L A 3

Percentagens com que a deficiencia nutricional e a diarréla entram, como causa básica ou associada, na mortalidade infantil, na mortalldade neonatal e na mortalidade pós-neonotal. São Paulo (1.0 Distrito), Recife e São Francisco (E.U.A.). Investigação Interamericana de Mortalidade na Infância, 1968-1970.

\begin{tabular}{|c|c|c|c|c|c|c|}
\hline \multirow{2}{*}{ Areas } & \multicolumn{3}{|c|}{ Deficiência nutricional } & \multicolumn{3}{|c|}{ Diarréia } \\
\hline & $\begin{array}{l}\text { Mortalidade } \\
\text { infantil }\end{array}$ & $\begin{array}{c}\text { Mortalidade } \\
\text { neonatal }\end{array}$ & $\begin{array}{l}\text { Mortalidade } \\
\text { pós-neonatal }\end{array}$ & $\begin{array}{l}\text { Mortalidade } \\
\text { Infantil }\end{array}$ & $\begin{array}{c}\text { Mortalidade } \\
\text { neonatal }\end{array}$ & $\begin{array}{l}\text { Mortalidade } \\
\text { pós-neonatal }\end{array}$ \\
\hline Sảo Paulo & $\begin{array}{l}28,0 \% \\
(\mathrm{~N}=3788)\end{array}$ & $\begin{array}{l}5,5 \% \\
(N=1958)\end{array}$ & $\begin{array}{l}52,1 \% \\
(N=1830)\end{array}$ & $\begin{array}{l}42,9 \% \\
(\mathrm{~N}=3788)\end{array}$ & $\begin{array}{l}24,7 \% \\
(N=1958)\end{array}$ & $\begin{array}{l}62,4 \% \\
(N=1830)\end{array}$ \\
\hline Recife & $\begin{array}{l}38,9 \% \\
(N=2773)\end{array}$ & $\begin{array}{l}3,9 \% \\
(N=1073)\end{array}$ & $\begin{array}{l}61,1 \% \\
(\mathrm{~N}=1700)\end{array}$ & $\begin{array}{l}52,5 \% \\
(\mathrm{~N}=2773)\end{array}$ & $\begin{array}{l}17,1 \% \\
(N=1073)\end{array}$ & $\begin{array}{l}74,9 \% \\
(N=1700)\end{array}$ \\
\hline São Francisco & $\begin{array}{l}3,3 \% \\
(N=209)\end{array}$ & $\begin{array}{l}0,0 \% \\
(N=147\end{array}$ & $\begin{array}{l}11,3 \% \\
(N=62)\end{array}$ & $\begin{array}{l}4,8 \% \\
(N=209)\end{array}$ & $\begin{array}{l}1,4 \% \\
(N=147)\end{array}$ & $\begin{array}{l}12,9 \% \\
(N=62)\end{array}$ \\
\hline
\end{tabular}

Fonte: Leser $^{3}(\mathbf{1 9 7 5 )}$

chegando a IV e voltando ao estágio II. Aumentou, assim, de dez anos, o nosso grau de atraso nas condições de saúde.

B - Outro conjunto de condicionantes é representado pela distribuição espacial e qualitativa dos equipamentos de saúde. Dentre as condições materiais de instalação destacam-se a "idade" de construção dos prédios, a forma de sua ocupação (se prédio próprio, alugado ou cedido) e os vazios; tal se dá porque as condiçóes materiais de instalação vão determinar, senão a composiçáo da equipe, pelo menus uma redução na velocidade necessária para adequar a equipe ao programa. Exemplos extremos serão a existência de equipamento dentário ou de raios $\mathrm{X}$ ou de laboratório onde não há o profissional ou onde não caberiam programas destacados e as recíprocas, representadas por inadequação de prédios. A "idade" de construção dos prédios nas condições de sua instalação (ver mapas 1, 2 e 3 ) revelam a adequação possível aos princípios da Reforma Administrativa que se processou na Secretaria de Estado da Saúde, com vistas a uma rede de unidades sanitárias polivalentes; nesse caso, prédios construídos anteriormente a 1967 e os que não são propriedade do Estado, revelam, em tese, disposição física não favorável à integração dos serviços.

A existência ou não de outras agências de saúde com programas decorrentes, conflitantes ou suplementares deve ser levada em conta no dimensionamento da equipe local de saúde, seja para refletir uma posição estratégica de "ter" o profissional presente em alguns casos, seja para diminuir o número de pessoas em algumas categorias, seja, ainda, para concentrar esforços em reforçar outras. A 
SA, E. N. de C. - Equipe local de saúde. Sugestões para a abrangência de sua caracterização. Rev. Salude pübl, S. Paulo, 10:75-102, 1976.

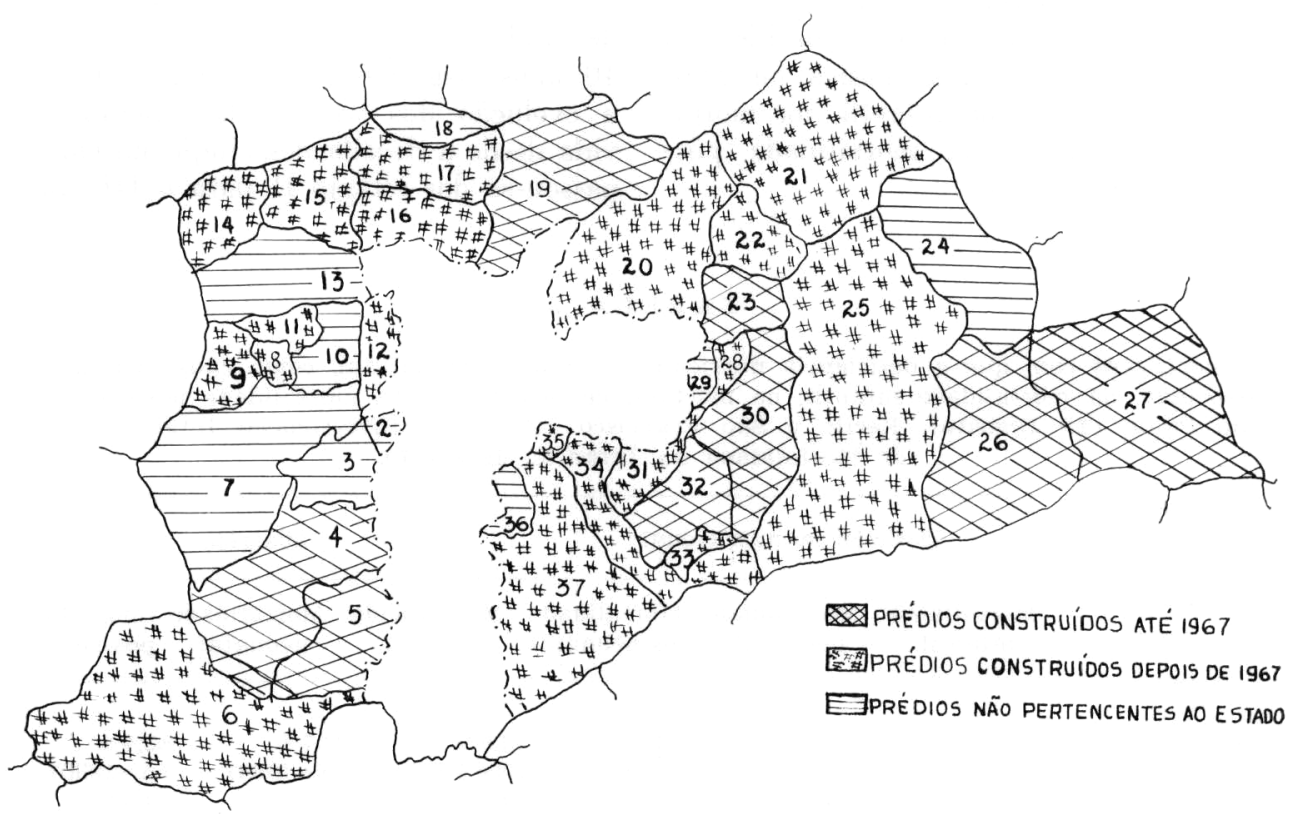

Fig. 8 - Idade de construção dos prédios das Unidades Sanitárias do DRS-I — Regiāo da Grande São Paulo, da Coordenadoria de Saúde da Comunidade, 1975.

Fonte: Assessoria do Gabinete do Secretário de Estado da Saúde; elaborado pelo Eng.o Hissao \Iomoi

ILapa básico elaborado pela Divisão de Estudos e Programas da CSC.

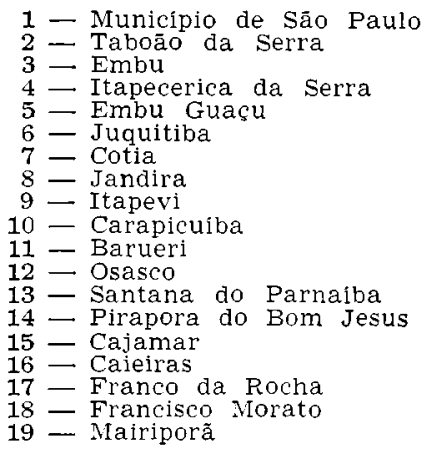

coexistência e a coordenação com outras agências refletirá uma programação de equipe em nível de decisão de governo como parte de um planejamento global.

Gonçalves ${ }^{1}$ trata do assunto quando estuda a distribuição dos equipamentos de saúde

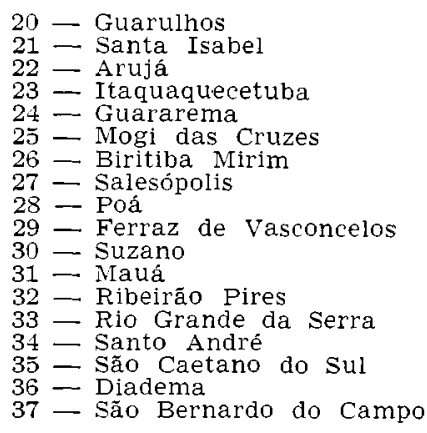

no Estado (Tabelas 4 e 5) e Yunes *, dá a distribuição das unidades do Instituto Nacional de Previdencia Social (INPS), dos Centros de Saúde da Secretaria de Estado da Saúde e do Departamento de

* Yunes, op. cit. 
SA, E. N. de C. - Equipe local de saúde. Sugestões para a abrangência de sua caracterização. Rev. Saúde públ., S. Paulo, 10:75-102, 1976.

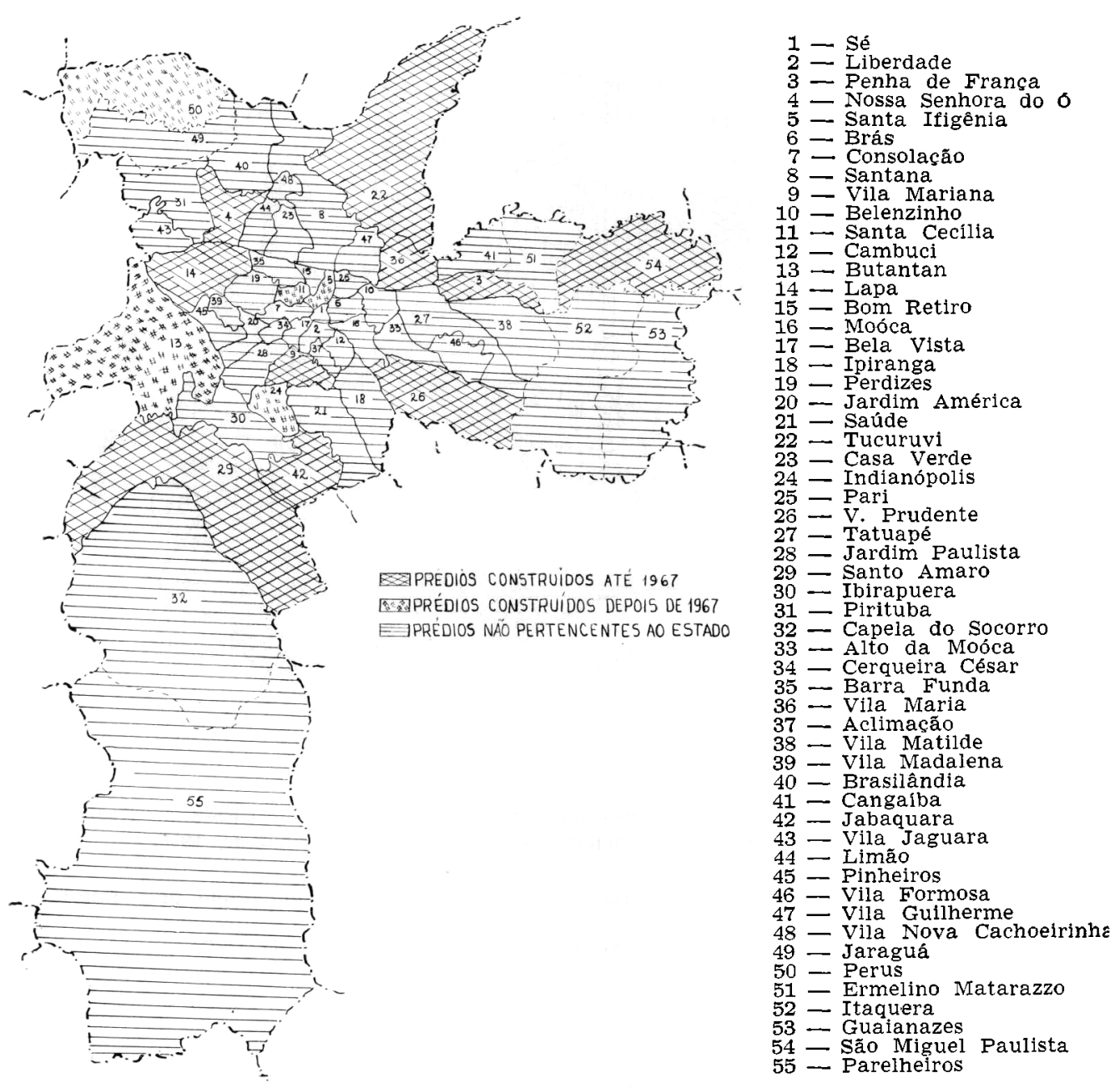

Fig. 9 - Idade das construções dos prédios das Unidades Sanitárias do DRS-1, do Município de São Paulo, 1975.

Fonte: Assessoria do Gabinete do Secretário de Estado da Saúde; elaborado pelo Eng. ${ }^{\circ}$ Hissao Momoi.

Mapa básico elaborado pela Divisão de Estudos e Programas da CSC.

Assistência à Infância e à Maternidade (DAIM) da Prefeitura Municipal de São Paulo, por zonas "central", "intermediária" e "periférica" no município (Tabela 6, Fig. 11).

Em nível estadual, São Paulo tem tido presença física em, pelo menos, uma agên- cia de prestação direta de serviços, tipo Centro de Saúde em quase todos os municípios do Estado. A área metropolitana tem uma distribuição espacial visivelmente defeituosa mostrando "vazios" de periferia (as Figs. 12, 13 e 14 ilustram essa distribuição por tipo de Centro). A amplitude 
SA, E. N. de C. - Equipe local de saúde. Sugestões para a abrangência de sua caracterização. Rev. Saúde públ., S. Paulo, 10:75-102, 1976.

TABELA 4

Distribuição global do equipamento de saúde vinculado ao INTPS no Estado de São Paulo

\begin{tabular}{|c|c|c|c|c|c|c|}
\hline \multirow{2}{*}{\multicolumn{2}{|c|}{ Regiões administrativas }} & \multirow{2}{*}{$\begin{array}{l}\text { N.o } \\
\text { Leitos }\end{array}$} & \multirow{2}{*}{$\begin{array}{c}\text { N.' } \\
\text { Médicos }\end{array}$} & \multicolumn{2}{|c|}{ Serv. compl. } & \multirow[b]{2}{*}{ Outros } \\
\hline & & & & L.C. & $\mathrm{R} \mathrm{X}$ & \\
\hline 1.8 & São Paulo & 15.934 & 1.669 & 104 & 38 & 74 \\
\hline $2 .^{a}$ & Santos & 2.244 & 223 & 13 & $\mathbf{5}$ & 6 \\
\hline $3 . .^{a}$ & São José dos Campos & 2.060 & 147 & 18 & $\tau$ & 6 \\
\hline $4 .^{\mathrm{a}}$ & Sorocaba & 2.794 & 143 & 13 & 9 & 4 \\
\hline $5 .{ }^{\mathrm{a}}$ & Campinas & 6.832 & 555 & 33 & 22 & 25 \\
\hline 6.9 & Ribeirão Preto & 4.587 & 384 & 18 & 15 & 26 \\
\hline 7.9 & Bauru & 1.863 & 177 & 7 & 8 & 9 \\
\hline $8 .^{\mathrm{a}}$ & São José do Rio Preto & 2.119 & 176 & 8 & 7 & 8 \\
\hline 9.9 & Aracatuba & 1.115 & 94 & 4 & 3 & 3 \\
\hline $10 .{ }^{8}$ & Presidente Prudente & 1.323 & 95 & 6 & - & 1 \\
\hline 11.8 & Marilia & 2.056 & 141 & 3 & 5 & 7 \\
\hline & Total & 42.927 & 3.804 & 227 & 119 & 169 \\
\hline
\end{tabular}

Fonte: Gonçalves 1, sobre dados da Coordenação de Assistência Médica - INPS São Paulo 1972-1973. 
SA, E. N. de C. - Equipe local de saúde. Sugestões para a abrangência de sua caracterlzação. Rev. Saúde pübl., S. Paulo, 10:75-102, 1976.

\section{TABELA 5}

Equipamento de saúde do IIunicipio de são Paulo

\begin{tabular}{|c|c|c|c|}
\hline Atividade & Equipamento & Vinculação & $\begin{array}{l}\text { N.O de } \\
\text { Unidades }\end{array}$ \\
\hline \multirow{4}{*}{$\begin{array}{l}\text { Assistência } \\
\text { médico-sanitária }\end{array}$} & Postos do DAIMI & s. Higiene e Saúde & 57 \\
\hline & Fiscalizaçāo Sanitária & $\begin{array}{l}\text { S. Abastecimento } \\
\text { (normativa) } \\
\text { COAR } \\
\text { (Execução descentrali- } \\
\text { zada) }\end{array}$ & - \\
\hline & $\begin{array}{l}\text { Centro de Controle } \\
\text { Zoonoses }\end{array}$ & S. Higiene e Saúde & 1 \\
\hline & $\begin{array}{l}\text { Consultórios em } \\
\text { balneários }\end{array}$ & S. Esportes & - \\
\hline \multirow{4}{*}{ Assistência hospitalar } & $\begin{array}{l}\text { Hospitais de Pronto } \\
\text { Socorro }\end{array}$ & S. Higiene e Saúde & 4 \\
\hline & Hospitais de Pediatria & S. Higiene e Saúde & 1 \\
\hline & Maternidade & S. Higiene e Saúde & 1 \\
\hline & $\begin{array}{l}\text { Hospital do Servidor } \\
\text { Público Municipal } \\
\text { (autarquia) }\end{array}$ & S. Higiene e saúde & 1 \\
\hline \multirow{5}{*}{$\begin{array}{l}\text { Assistência } \\
\text { para-hospitalar }\end{array}$} & $\begin{array}{l}\text { Postos de Pronto } \\
\text { Socorro }\end{array}$ & S. Higiene e Saúde & 6 \\
\hline & $\begin{array}{l}\text { Centro de Controle } \\
\text { de Intoxicaçoes }\end{array}$ & S. Higiene e Saúde & 1 \\
\hline & $\begin{array}{l}\text { Serviço de Recuperação } \\
\text { dos Alcoólatras }\end{array}$ & S. Higiene e Saúde & 1 \\
\hline & $\begin{array}{l}\text { Assistêneia escolar: } \\
\text { médica e odontológica }\end{array}$ & S. Educação e Cultura & - \\
\hline & Merenda Escolar & S. Educação e Cultura & - \\
\hline
\end{tabular}

Fonte: Gonçalves ! 
SA, E. N. de C. - Equipe local de saúde. Sugestóes para a abrangência de sua caracterízação. Rev. Saúde públ., S. Paulo, 10:75-102, 1976.

T A B E L A 6

Relação das Unidades Sanitárias, Unidades do INPS, Unidades do DAIM, segundo localização, no municíplo de São Paulo, em 1971

\begin{tabular}{|c|c|c|c|c|c|c|c|c|}
\hline \multirow{2}{*}{ Zonas $\begin{array}{c}\text { Unidades } \\
\text { atendimento }\end{array}$} & \multicolumn{5}{|c|}{ DRS-I } & \multirow{2}{*}{ INPS } & \multirow{2}{*}{ DAIM } & \multirow{2}{*}{ Total } \\
\hline & C.S.I & C.S.II & C.S.III & C.S.IV & C.s.v & & & \\
\hline Zona Central & 5 & 1 & 3 & 1 & 8 & 13 & 5 & 36 \\
\hline Zona Intermediária & 7 & 1 & 5 & 6 & 59 & 7 & 26 & 111 \\
\hline Zona Periférica & 2 & 4 & 2 & 8 & 29 & 一 & 17 & 62 \\
\hline Total & 14 & 6 & 10 & 15 & 96 & 20 & 48 & 209 \\
\hline
\end{tabular}

Fonte: Yunes, op. cit.

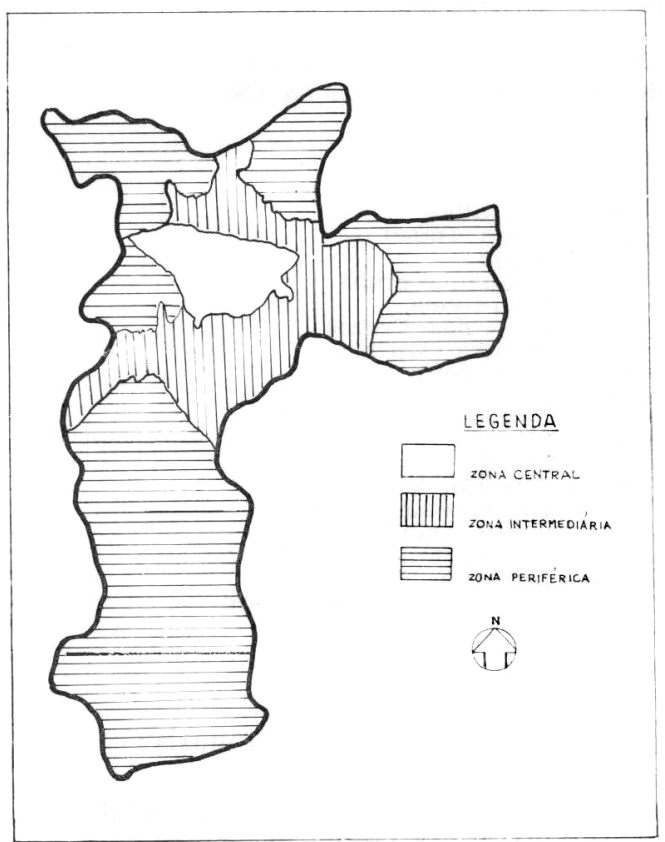

Fig. 11 - Divisão do Município de São Paulo em zonas

Fonte: Yunes, op. cit. da rede no interior é sugestiva da cobertura possível em termos de programa a serem desenvolvidos.

EQUIPE LOCAL DE SAOUDE EM UNIDADE SANITARIA POLIVALENTE. A EXPERIENCIA DA SECRETARIA DE ESTADO DA SAODE EM SAO PAULO

\section{A - Programas e quantificação dos recursos humanos.}

A Secretaria de Estado da Saúde no Estado optou, dentre as diretrizes de reforma administrativa por que passou, por uma integração dos serviços de saúde prestados à população em nível local, adotando o Centro de Saúde como unidade polivalente e dinâmica, sob chefia única, classificados segundo os programas de saúde que lhes cumpre executar.

Os programas estão assim detalhados:

A. 1 - programa desenvolvido - CS-I:

a) controle de doenças transmissíveis; 
SÅ, E. N. de C. - Equipe local de saúde. Sugestôes para a abrangência de sua caracterização. Rev. Salude puibl., S. Paulo, 10:75-102, 1976.

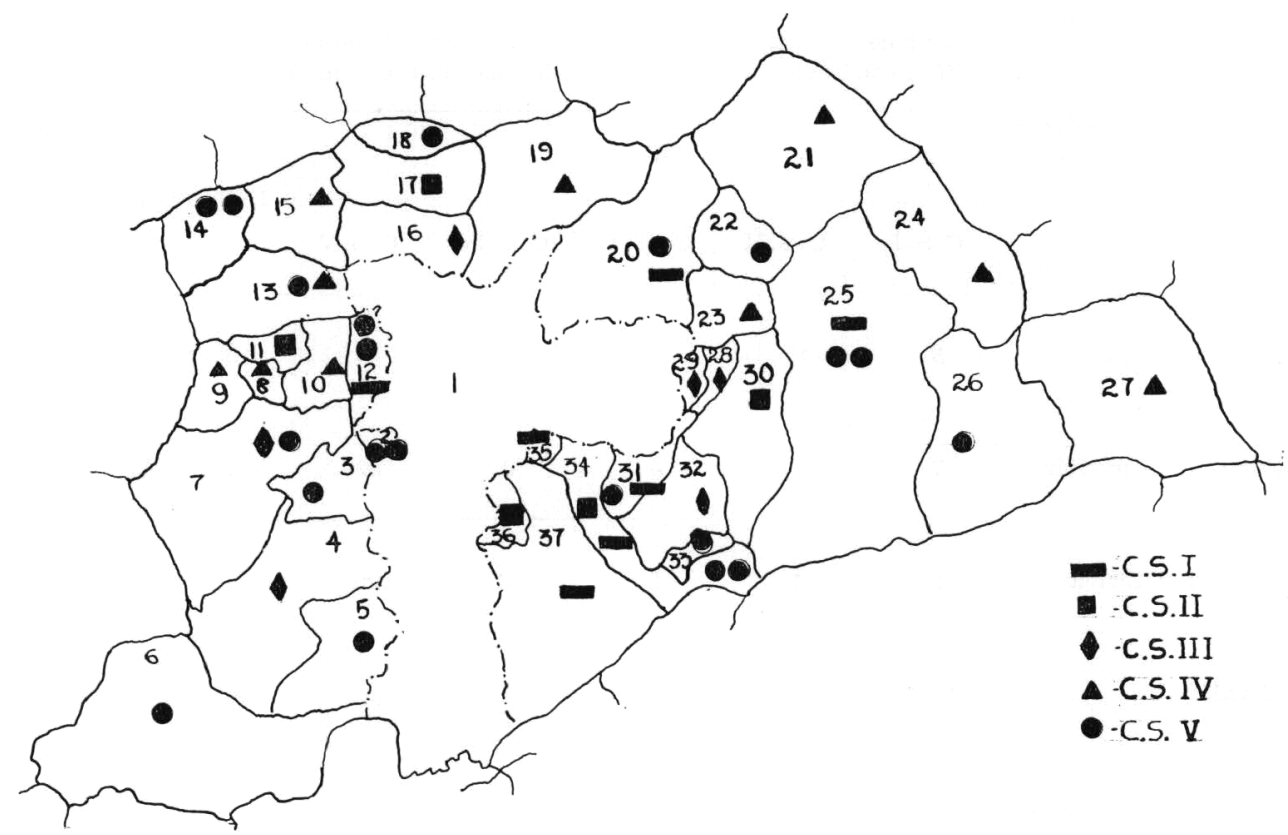

Fig. 12 - Tipos de Unidades Sanitárias do DRS-1, Região da Grande São Paulo,

da Coordenadoria de Saúde da Comunidade, 1975

Fonte: Assessoria do Gabinete do Secretário de Estado da Saúde, com dados da CsC. Mapa básico elaborado pela Divisão de Estudos e Programas da CSC.

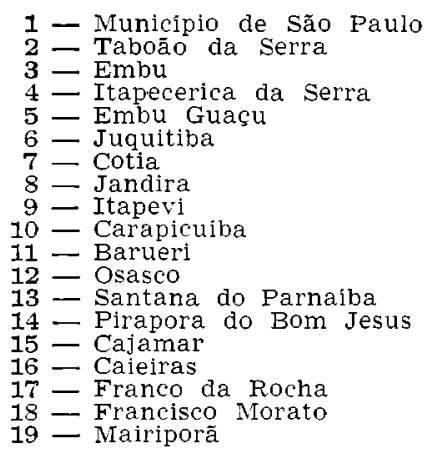

b) saneamento do meio;

c) higiene materna e da criança;

d) assistência médica sanitária especializada;

e) controle da tuberculose;

f) controle da saúde mental; da hanseníase;

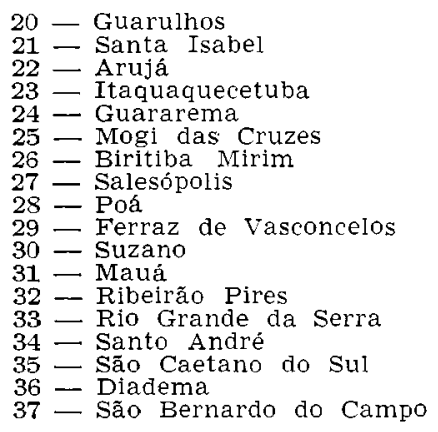

g) odontologia sanitária;

h) nutrição;

i) epidemiologia e estatística;

j) enfermagem;

l) educação sanitária;

m) laboratório;

n) administração. 
SA, E. N. de C. - Equipe local de saúde. Sugestões para a abrangência de sua caractertzação. Rev. Saúde públ., S. Paulo, 10:75-102, 1976.
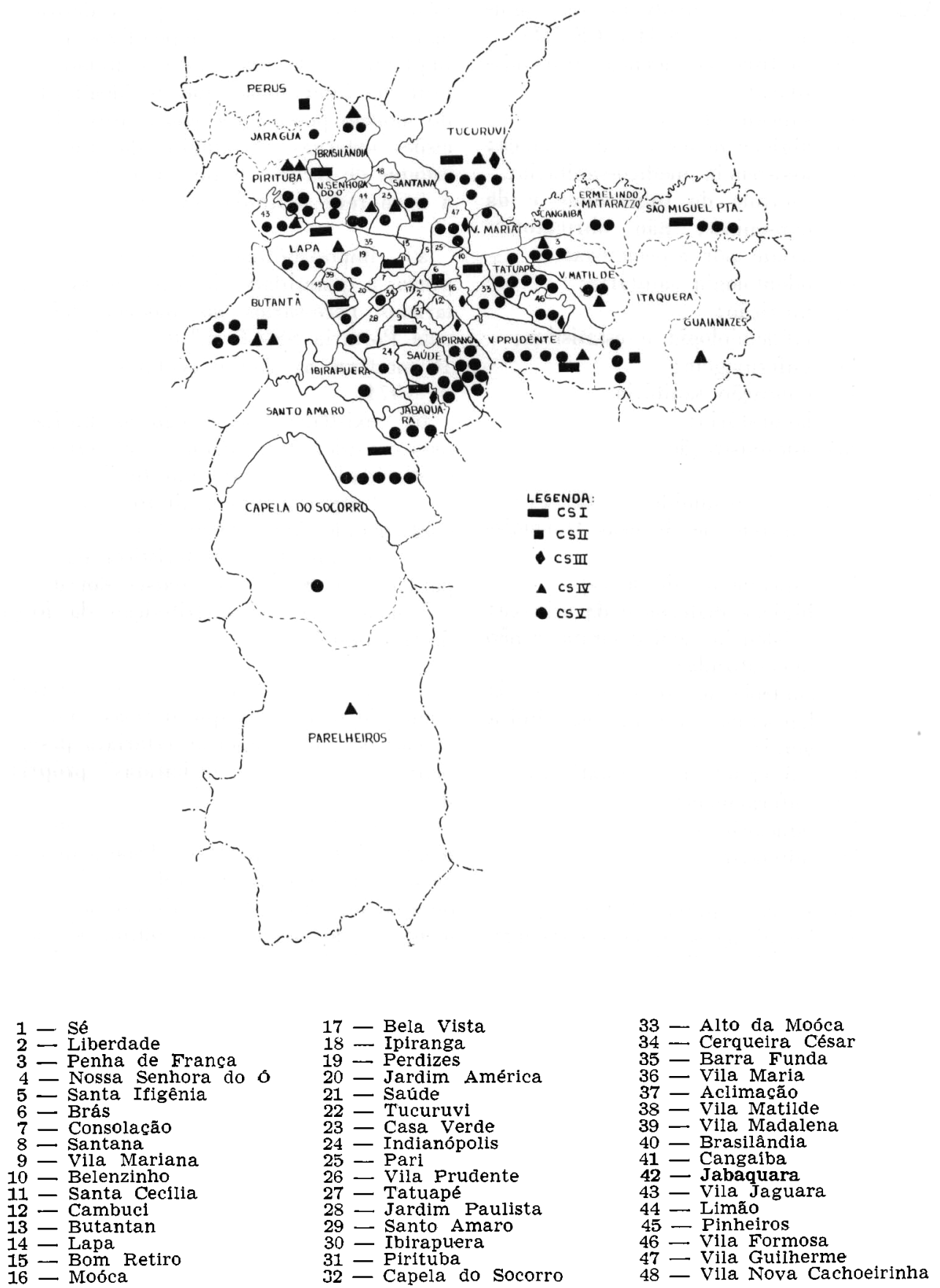

Fig. 13 - Tipos de Unidades Sanitárias do DRS-1, do Município de São Paulo, 1975

Fonte: Assessoria do Gabinete do Secretário de Estado da Saúde, com dados da CSC. Mapa básico elaborado pela Divisão de Estudos e Programas da CSC. 
SA, E. N. de C. - Equipe local de saúde. Sugestōes para a abrangência de sua caracterização. Rev. Saúde puibl., S. Paulo, 10:75-102, 1976.

A.2 - programa desenvolvido com algumas exceções: CS II e CS [II:
a) controle de doenças transmis- síveis;
b) saneamento do meio;
c) higiene materna e da criança;
d) assistência médico-sanitária;
e) controle da tuherculose e da hanseníase, não obrigatoria- mente por especialistas;
f) odontologia sanitária;
g) nutrição;
h) epidemiologia e estatística;
i) enfermagem;
j) educação sanitária;
l) laboratório;
m) administração.

A.3 - programa resumido - CS IV:

a) controle de doenças transmissíveis:

b) saneamento do meio:

c) higiene materna e da criança;

d) assistência médico-sanitária não especializada;

e) controle da tuberculose e da hanseniase a cargo de clínica geral:

f) epidemiologia e estatística;

g) enfermagem;

h) educação sanitária;

i) administração.

A. 1 - programa mínimo - CS V:

a) imunizações e, eventualmente. quimioprofilaxia;

b) saneamento do meio;

c) visitação sanitária;

d) educação sanitária;

e) assistência médico-sanitária fixa ou intermitente.

A Tabela 7 discrimina as faixas de população, as categorias profissioncis e a quantificação de equipes previstas para cada tipo de Centro de Saúde.

\section{B - Situação de instalação.}

A fase de implantação de um modelo permite medir o grau de ajuste do pró- prio modelo à realidade a que se destinou; aparecem, também, os impeditivos à plena implantação de uma nova realidade e o grau de intervenção que os idealizadores do modelo possam ter nos centros de decisōes externas. A análise do ajuste do estoque de recursos humanos da Secretaria à nova rede definida revela:

a) impossibilidade de formar, a curto prazo. a quantidade de profissionais sanitaristas necessários ao modelo definido pela Portaria SS-CG n. ${ }^{\circ}$ 8; as Figs. 15 e 16 mostram as chefias acéfalas em março de 1974 .

b) existência de categorias profissionais consideradas "médias" em termos de escolaridade formando um funil entre as de nível superior e as auxiliares, (Fig. 17) confirmando Mascarenhas ${ }^{\bar{j}}$ ao citar esse fato como um dos característicos da equipe local de Saúde nos países em desenvolvimento. De tal distribuição da força de trabalho infere-se:

- que esteja havendo um encarecimento do serviço, já que pessoas com formação de curso superior estariam desempenhando tarefas "mas haratas" próprias de pessoal de nível médio e

- que esteja havendo um enriquecimento ilícito por parte do Estado quando pessoas desempenham tarefas mais caras do que aquelas pelas quais estejam realmente sendo pagas. Esta última situação é. além de imoral. ilegal. já que o desvio de função é expressamente redado pelo Estatuto dos Servidores Públicos Civis do Estado:

c) impossibilidade de corrigir os desrios de função e os desajustes quantitatiros de profissionais disponíveis na unidade e que não estejam previstos no modelo. A Tabela 8 mostra os desvios da disponibilidade profissional quantitativa frente ao modelo e aos desvios de função, evidentes em alguns casos e presumíveis em outros. A coluna rotulada "OUTROS" compreendia, em 1973, 33 categorias profissionais não previstas no modelo, e custando, na época Cr\$ 155.00 mensais. sob 


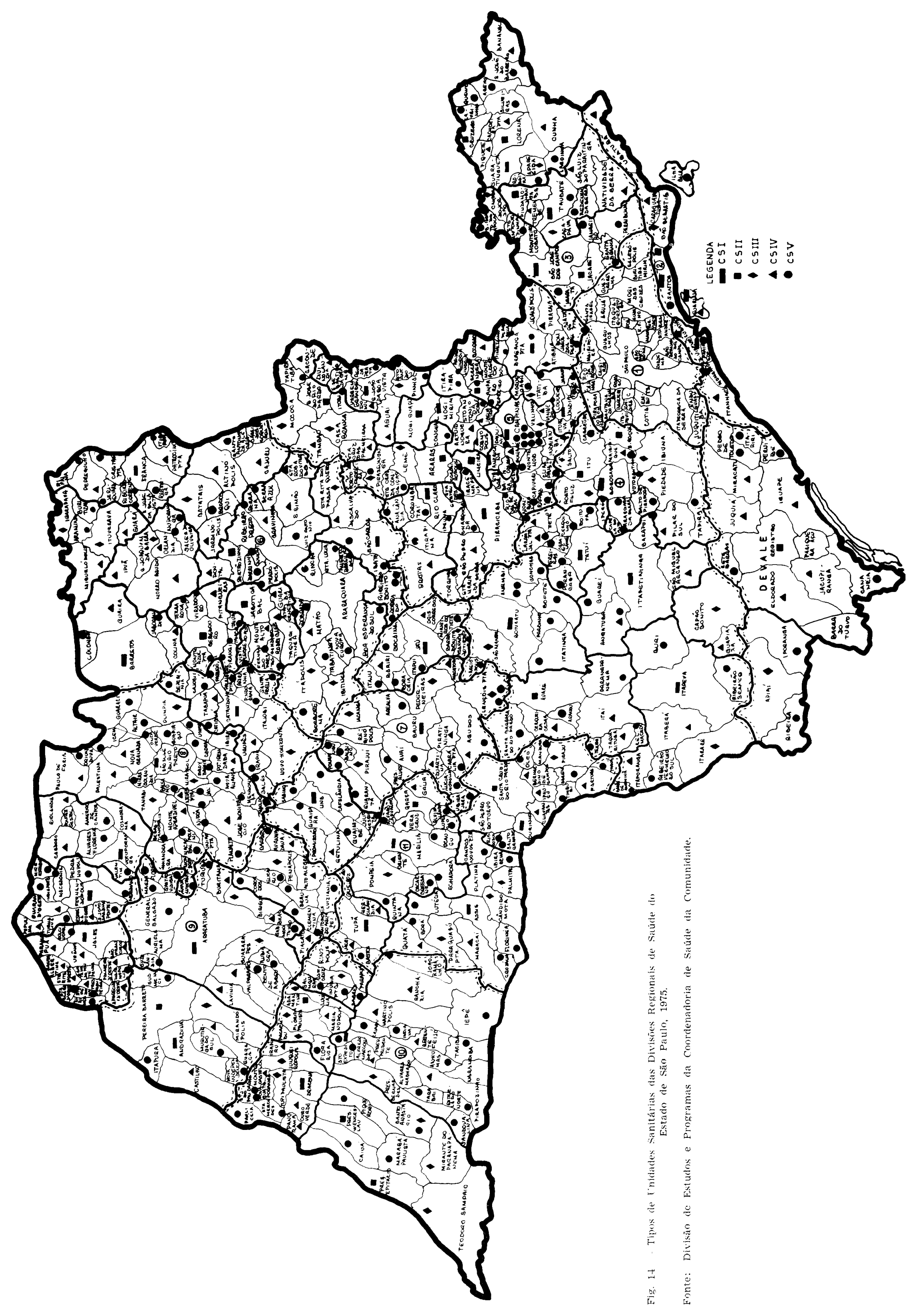


SA, E. N. de C. - Equipe local de saúde. Sugestões para a abrangência de sua caracterização. Rev. Saúde públ., S. Paulo, 10:75-102, 1976.

T A B E L A 7

Categorias profissionais por tipo de Centro de Saúde, segundo o modelo da Portaria SS-CG n.o 8, de 6-6-72

\begin{tabular}{c|c|c|c|cc}
\hline Tipo de U.S. & CS I & CS II & CS III & CS IV & CS V \\
& População & População & População & População & População \\
& 50 mil a & 30 mil a & 20 mil a & 10 mil a & até 10 mil \\
& 150 mil & 50 mil & 30 mil & 20 mil & habitantes \\
habitantes & habitantes & habitantes & habitantes & hatias \\
\hline
\end{tabular}

Médico Chefe Sanitarista III

Médico Chefe Sanita-

rista II

Médico Auxiliar Sani-

tarista I

Médico Consultante -

Saúde da Criança

Médico Consultante -

Saúde Materna

Médico Consultante

Tisiologista e Pneumo-

logista

Médico Consultante

Dermatologista e

Hanseniologista

Médico Consultante

Oftalmologista

Médico Consultante

Psiquiatra

Médico Consultante

Clínico Geral

Médico Consultante

Otorrinolaringologista

Psicólogo

Assistente Social

Enfermeira

Obstetriz

Cirurgião Dentista

Operador de Raio X

Técnico de Laboratório

Educador Sanitário

Auxiliar de Laboratório

Inspetor de Saneamento

Fiscal Sanitário

Visitador Sanitário

Atendente

Escriturário

Vigia

Motorista

Servente

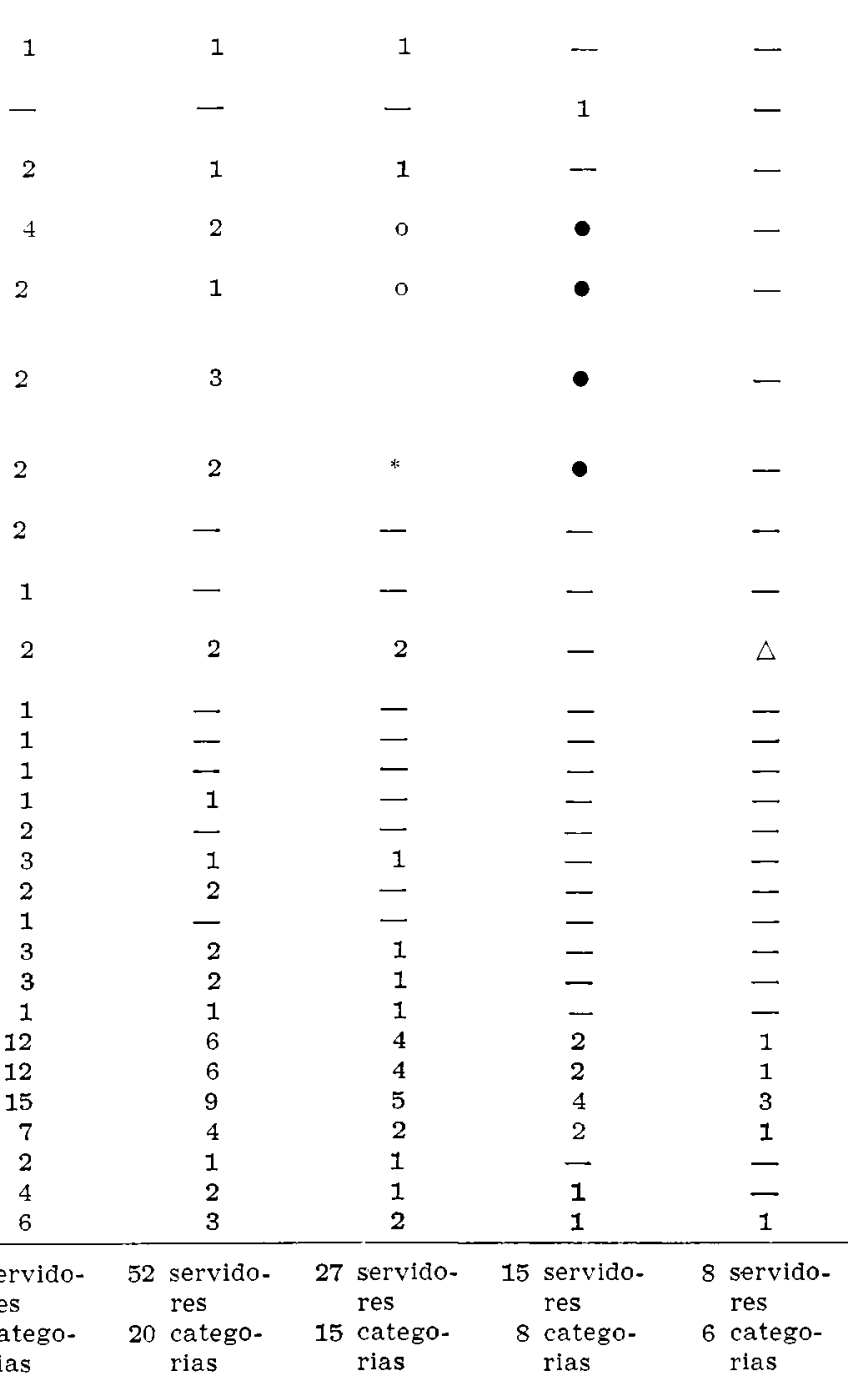

TotaI

$\begin{aligned} 27 & \text { catego- } \\ & \text { rias }\end{aligned}$

rias

rias

rias

rias

- 1 Médico Consultante com adestramento nas áreas de saúde materna e da criança.

* 2 Médicos Consultantes, Clínicos Gerais para atendimento de adulto com experiência em Dermatologia Sanitária, Hanseniologia, Tisiologia e Pneumologia.

- 2 Médicos Consultantes, com experiêncla nas áreas de saúde materna, da criança, de adultos, dermatologia sanitária, hanseniologia, tisiologia e pneumologia.

$\triangle 1$ Médico fixo ou intermitente. 
SA, E. N. de C. - Equipe local de saúde. Sugestões para a abrangência de sua caracterização. Rev. Saúde públ., S. Paulo, 10:75-102, 1976.

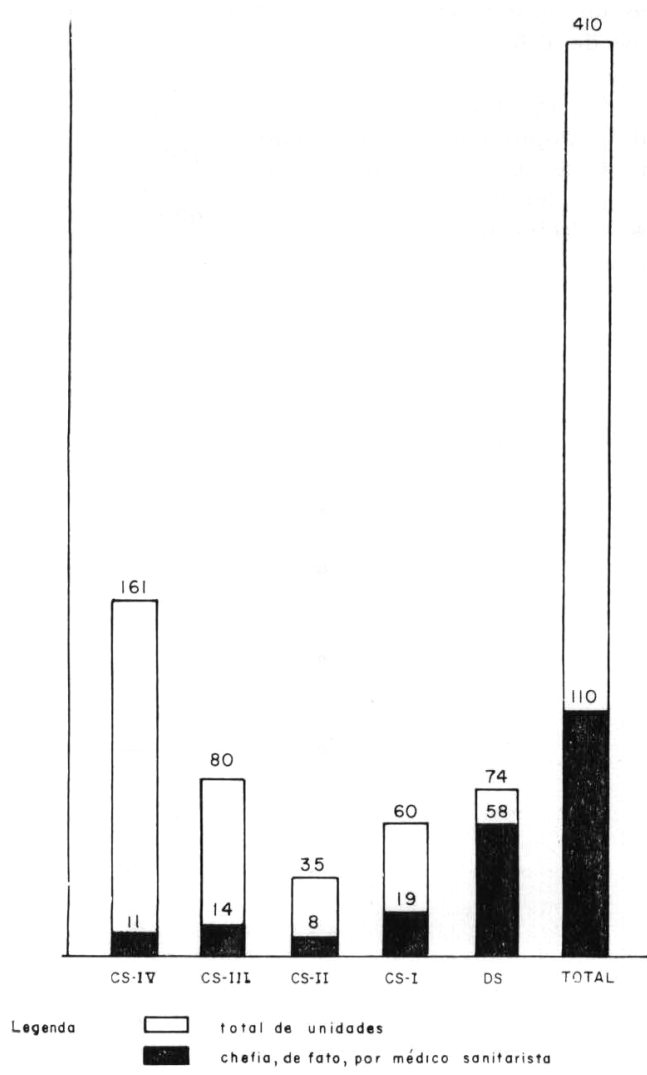

Fig. 15 - Situação das chefias de Unidades Sanitárias da Secretaria de Estado da Saúde em março de 1974

Fonte: Gonçalves ${ }^{1}$ e Leser ${ }^{4}$, sobre dados da C-AP elaborados pelo D.T.N.

as seguintes denominações: auxiliar de enfermagem, auxiliar de higiene dental, auxiliar de saneamento, auxiliar de farmacêutico, auxiliar de dietética, auxiliar de fiscal sanitário, auxiliar técnico administrativo, almoxarife, artífice, agente da FEPASA, assistente de administração, biologista, bibliotecário, contínuo-porteiro, chefe de serviço, chefe de seção, chefe de estação, conferente, desenhista, desinsetizador, encarregado de setor, farmacêutico, gráfico, marceneiro, nutricionista, operário, operador de telecomunicações, mestre, prático de laboratório, reparador

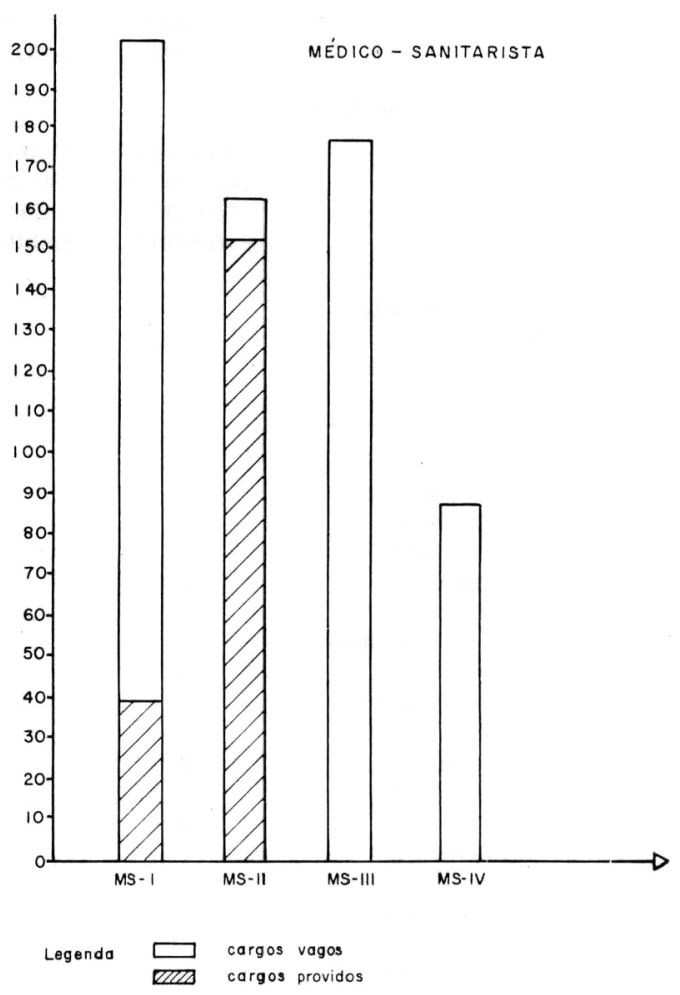

Fig. 16 - Cargos vagos e providos na carreira de Médico Sanitarista da Secretarla de Estado da Saúde em março de 1974

Fonte: Gonçalves * e Leser ${ }^{4}$, sobre dados da C-AP elaborados pelo D.T.N.

geral, rádio-telegrafista, trabalhador braçal, telefonista, técnico de ortótica e zelador.

As diferenças de denominação mostram que, em alguns casos, as atribuições estavam muito próximas das ideais previstas, como no caso de "auxiliar de higiene dental", "auxiliar de saneamento" etc. e que seriam, provavelmente, indicativas de que as pessoas estariam desempenhando, de fato, funções de atendente e fiscal sanitário. Em outros casos, são totalmente inadequados aos programas descritos. 0 que se nota em todos os casos de excedentes é que existe uma "herança" de situações cuja solução não está ao alcance 
SA, E. N. de C. - Equipe local de saúde. Sugestões para a abrangêncla de sua caracterização. Rev. Saúde públ., S. Paulo, 10:75-102, 1976.

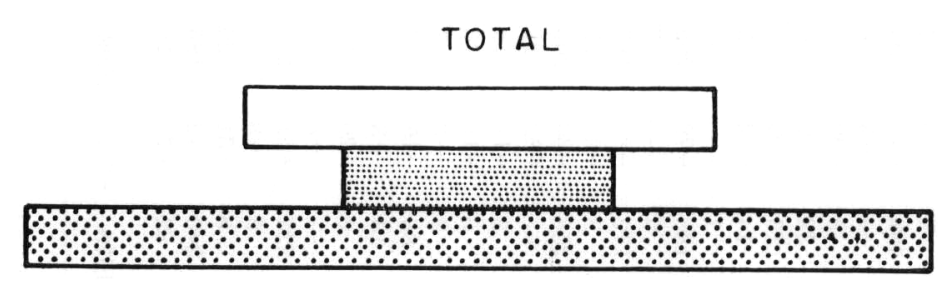

NO SERVIDORES

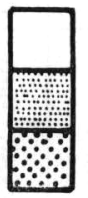

4.734

2.565

9.393

PESSOAL EFETIVO

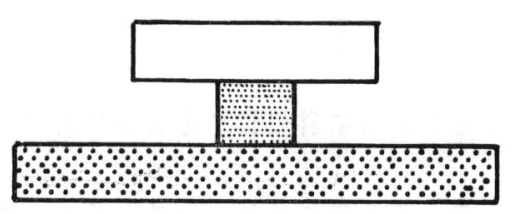

N2 SERVIDORES

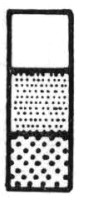

2.451

712

4.622

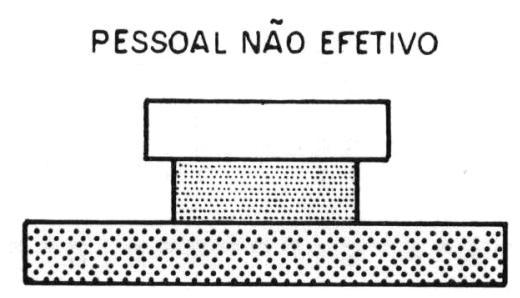

Ne SERVIDORES

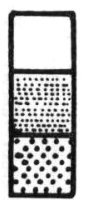

2.283

1.853

4.771

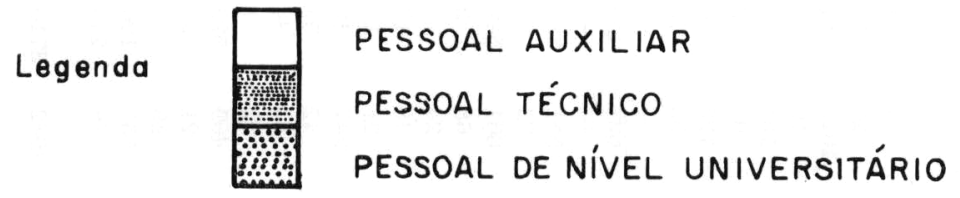

Fig. 17 - Distribuição do pessoal do serviço de saúde por nivel de escolaridade. 


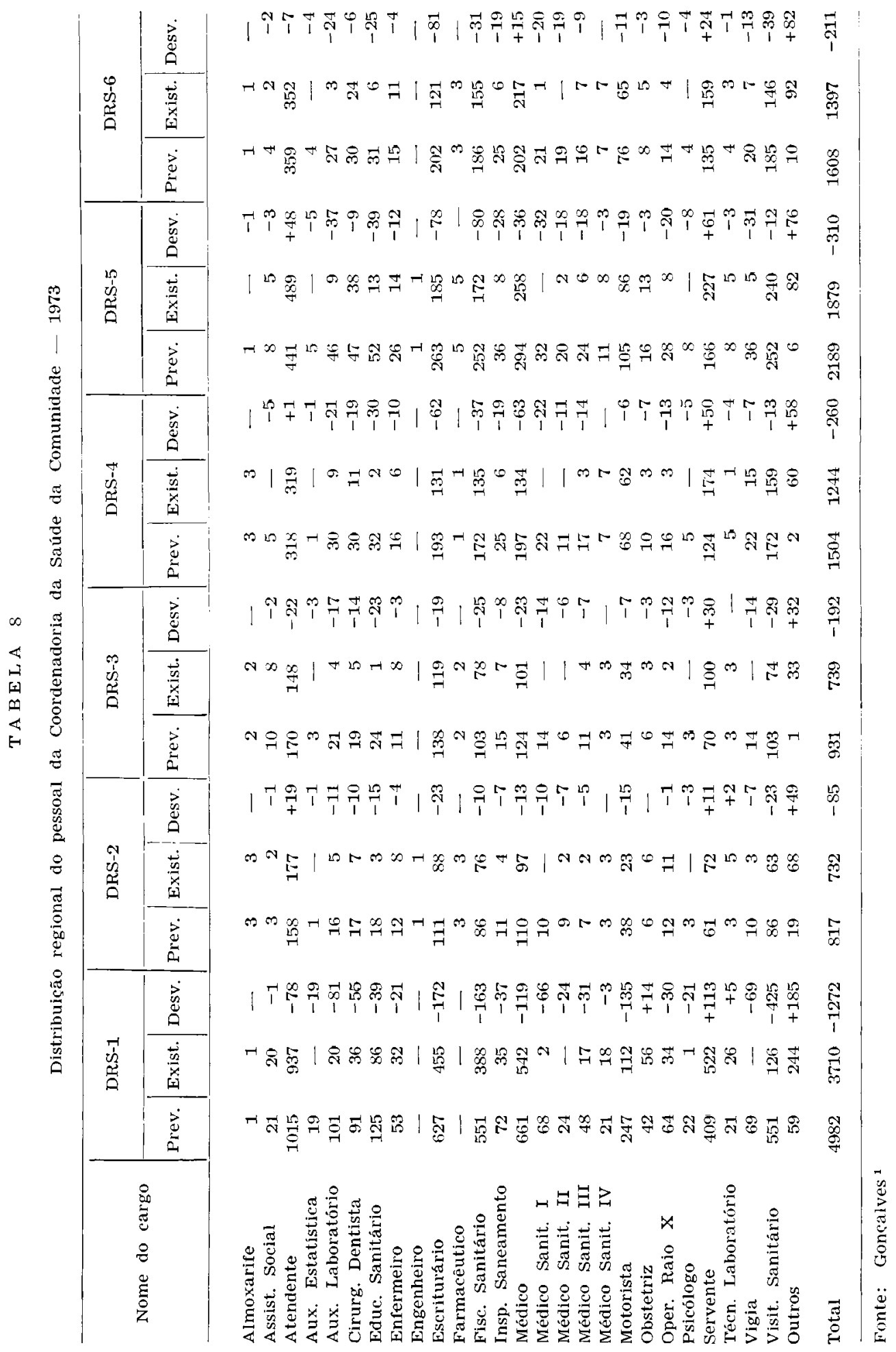




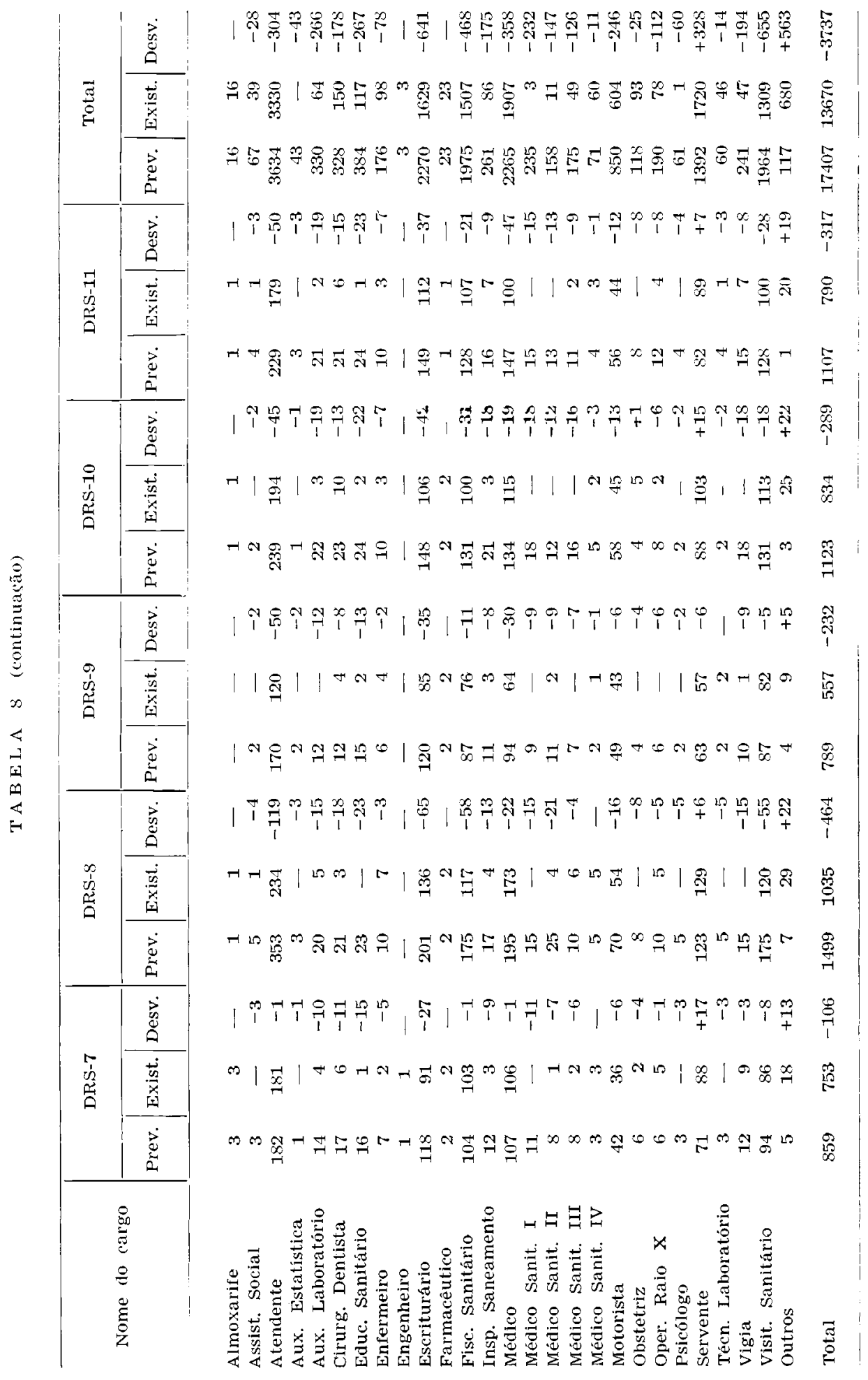


SA, E. N. de C. - Equipe local de saúde. Sugestões para a abrangência de sua caracterização. Rev. Saúde públ., S. Paulo, 10:75-102, 1976.

de quem definiu o modelo da equipe local de saúde;

d) há desvios numéricos, geralmente para menos, quando são comparados o estoque de pessoal existente e o modelo dado pela Portaria SS-CG 8/72 (Tabela 8). As diferenças numéricas para me- nos nas categorias previstas podem ser interpretadas de duas maneiras: ou o modelo está superdimensionado, gerando diferenças artificiais para menos na comparação ou os programas não foram implantados ou demandados para as populações previstas, permitindo que a rede funcione como vem funcionando.

SÁ, E. N. de C. - [The local heath tean. Rev. Saúde públ., S. Paulo, 10:75-102, 1976.

SUMMARY: The S. Paulo State Health Department is undergoing an analysis as regards the present model used for manpower dimensioning throught it network of Sanitary units. Putting in a model will point ont the degree of correct forecasting as to difficulties and external interference such as the availability of human resources on the market and the possibility of competing wich this market.

UNITERMS: Health, local staff. Health Center, local. Public Health.

\section{RETERENCIAS BIBLIOGRAFICAS}

1. GONCALVES, E. L. et al. - Estrategia operacional de governo (proposiçozes); relatório da área de saúde. São Paulo, Governo do Estado de São Paulo, 1974.

2. GUEDES, J. da S. \& GUEDES, M. L. da S. - Quantificaçăo do indicador de Nelson de Moraes (curva de mortalidade proporcional). Rev. Saúde públ., S. Paulo, 7:103-13, 1973.

3. LESER, W. S. P. - Crescimento da população da cldade de São Paulo, entre 1950 e 1970, e seu reflexo nas condições de saúde pública. Ciênc. e Cultura, 27:244-56, 1975.

4. LESER, W. S. P. et al. - Regic̃o metro- politana de São Paulo diagnóstico saúde-1975. São Paulo, Governo do Estado de São Paulo, 1974.

5. MASCARENHAS, R. dos S. et al. - Introduৎ̣ão à administração sanitária. São Paulo, Faculdade de Saúde Pública, Disciplina de Administração Sanitária, 1972 [apostila mimeografada].

6. RODRIGUES, B. A. - Fundamentos de administração sanitaria. Rio de Janeiro, Ed. Freitas Bastos, 1967.

Recebido para publicação em 08/09/1975 Aprovado para publicaç̃o em 22/09/1975 